\title{
DEVELOPMENT OF CLADDING CONTRIBUTION FUNCTIONS FOR SEISMIC LOSS ESTIMATION
}

\author{
Shreedhar Khakurel ${ }^{1}$, Trevor Z. Yeow ${ }^{2}$, Frankie Chen $^{3}$, Zam \\ Wang $^{4}$, Sandip K. Saha ${ }^{4}$ and Rajesh P. Dhakal ${ }^{5}$
}

(Submitted March 2018; Reviewed June 2018; Accepted December 2018)

\begin{abstract}
One method to rapidly estimate seismic losses during the structural design phase is to use contribution functions. These are relationships between expected losses (e.g. damage repair costs, downtime, and injury) for a wide range of building components (e.g. cladding, partitions, and ceilings) and the building's response. This study aims to develop contribution functions for common types of cladding used in different types of buildings considering damage repair costs. In the first part of this study, a building survey was performed to identify types and quantity of cladding used in residential, commercial and industrial buildings in Christchurch, New Zealand; where it was found that the most common cladding types are glazing, masonry veneer, monolithic cladding and precast panels. The data collected during the survey was also used to develop cladding distribution (i.e. density) functions. The second step involved identifying fragility functions from relevant literature which are applicable to the cladding detailing used in New Zealand. The third step involved surveying consultants, suppliers and builders on typical repair/replacement cost. Finally, Monte Carlo simulations were performed to combine the cladding density function with the fragility functions and the repair cost for each type of cladding to derive contribution functions for various types of cladding and building usage. An example (case study) is provided to demonstrate its usage.
\end{abstract}

\section{INTRODUCTION}

The building envelope is the skin of the building which consists of external walls, doors, windows, roof, and lowest floor of the building. Cladding systems are non-structural building components which describe the external wall including the support mechanism back to the structure. Claddings serve the basic purposes of providing thermal insulation and weather resistance in addition to providing architectural features [1]. Furthermore, aspects such as lighting and ventilation are directly affected by the claddings used, which have a large influence on user comfort [2]. Due to these reasons, any damage to the cladding system would affect the building's integrity which may disrupt building usage until repairs are completed. Moreover, damage to cladding systems may also pose lifesafety risk outside the building.

In recent seismic events around New Zealand, such as the 20102011 Canterbury earthquake sequence, it has been observed that cladding can incur significant damage during seismic shaking [1,3]. This is because cladding systems often incorporate stiff and brittle materials such as glass, concrete and stone [4] which incurs damage under small distortions. Due to this, it is important to consider the performance of cladding when evaluating the socioeconomic impacts of a building's response during seismic shaking.

Cladding systems are just one of the many building components which may get damaged during strong shaking events despite the structural system itself performing well. This has raised awareness of the need to minimise socioeconomic impacts in future events to increase resilience. One way to achieve this is to explicitly consider seismic losses during the building design phase. One of the most widely used seismic loss estimation methodologies is the Pacific Earthquake Engineering Research (PEER) centre's Performance Based Earthquake Engineering
(PBEE) framework [5]. This framework comprises of four key analysis steps; (i) calculating the frequency of a seismic shaking intensity being exceeded, (ii) performing structural analyses to predict the building's response under a given shaking intensity, (iii) estimate component damage based on the building's response, and (iv) predict the losses resulting from the estimated damage. Step (iii) requires the use of fragility functions, which are probabilistic distributions describing the probability of exceeding certain damage levels based on the building's response; while step (iv) requires loss distributions, which are cumulative distribution of losses for a given damage level. Examples of fragility and loss functions are shown in Figures $1 \mathrm{a}$ and $1 \mathrm{~b}$, respectively.

The difficulties of applying this framework in engineering practice are (i) information regarding the quantity and type of every single building component are often not known by the engineer at the design stage, (ii) fragility and loss functions can be difficult to source, and (iii) a good understanding of probabilistic computation is needed. One method to avoid these issues is to provide engineers with typical loss distributions which can be related directly to building response for different building usages. Such an approach has been previously proposed by Dhakal [6] and refined by Dhakal and Saha [7], where the component losses were provided as a ratio of each storey's value which inherently includes information on the type and quantity of the components, and their fragility/loss functions. These ratios represent the contribution of component losses to the storey-level losses, and as such can be simply added together to estimate the losses incurred on a single storey level. However, the terminology used to describe these new functions is similar to loss functions, which can create some confusion in distinguishing between the two. As such, the term "contribution functions" is introduced in this paper to describe these new distributions, and is described in more detail in later

\footnotetext{
1 PhD Candidate, University of Canterbury, Christchurch, shreedhar.khakurel@pg.canterbury.ac.nz

2 Postdoctoral Researcher, University of Canterbury, Christchurch, trevor.yeow@canterbury.ac.nz

3 Ex-Undergraduate Student, University of Canterbury, Christchurch

4 Assistant Professor, Indian Institute of Technology Mandi, Mandi, sandip_saha@iitmandi.ac.in (Member)

5 Professor, University of Canterbury, Christchurch, rajesh.dhakal@canterbury.ac.nz (Fellow)
} 
sections. It should be noted that there are also other options available to simplify seismic loss estimation approaches [8], but these are not elaborated in further detail here.

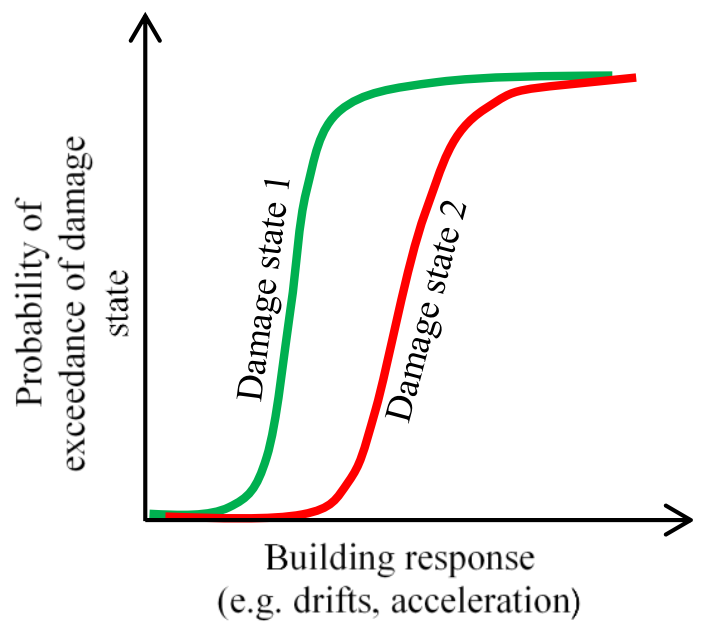

(a)

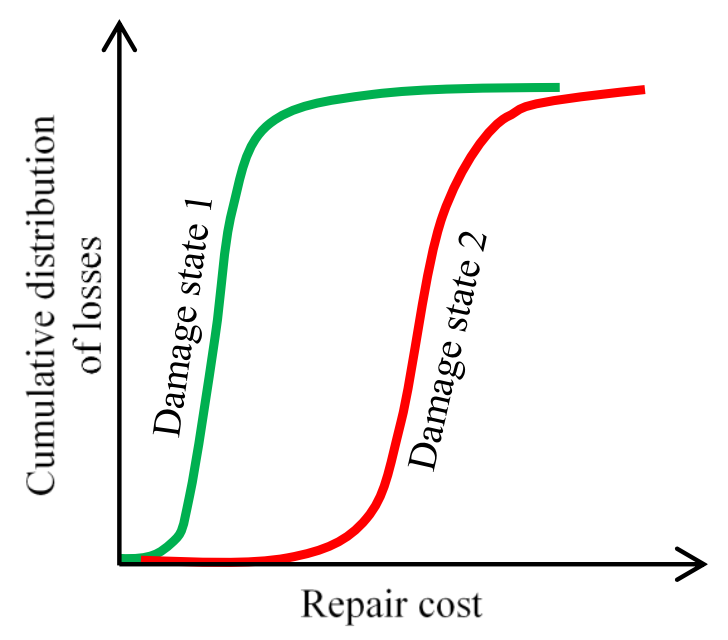

(b)

Figure 1: Functions required in rigorous componentbased seismic loss estimation; (a) fragility functions, and (b) loss distributions.

For this simplified approach to be widely adopted in practice, contribution functions need to be developed for a wide range of different building components. Contribution functions for ceilings and partitions have been developed and proposed by Dhakal et al. [9]. Due to the importance of cladding systems as previously described, there is also a need to develop contribution functions for these systems. The aim of this study is to address this need, and it involves identifying (i) the most common types of claddings used in various building usage types, (ii) the typical quantity/density of claddings used in these building types, (iii) relevant fragility functions for each cladding type, and (iv) repair cost estimates for each damage type. These datasets are later combined to develop contribution functions, and an example demonstrating the application of the contribution functions is provided.

\section{CLADDING TYPES}

There are multiple types of cladding systems. It is quite difficult to distinguish them from one another, as there are different materials that can be used for cladding. Commonly used cladding materials are brick, glass, metal, concrete, timber, stone, vinyl, and composite materials that can include aluminium, wood, blends of cement and recycled polystyrene, wheat/rice straw fibres. The cladding systems can also be installed using different methods, which are adapted to different kinds of materials used in the construction of the cladding system.

\section{Glazing}

Stick curtain (continuous) and curtain wall (discrete) cladding systems are the most common types of glazing used in New Zealand. They are made of aluminium framing and glass panels connected back to the building structure. Heat soaked glass is used in these types of glazing to reduce the spontaneous breakage and the subsequent glass fallout; thereby reducing the associated replacement, maintenance and disruption costs and the risk of the building being classified as unsafe. Unitised curtain walls are composed of large glass units and are glazed within a factory and then sent to the construction site. Once on site, the units are hoisted onto anchors connected to the building. Unitised curtain walls have the advantages of faster construction, lower installation costs and better quality control, however, they can be more expensive than other systems [4].

The stick curtain, or stick system, is a metal 'stick' frame consisting of continuous perpendicular transoms and mullions surrounding pieces of glass or thin opaque panels. The vast majority of low to mid-rise curtain walls are installed in this way. Long pieces of aluminium (hence the name stick) are inserted between floors vertically and horizontally between vertical members to support and transfer the load of the glass back to the structure. Stick curtains are a popular option in multi-storey buildings and are often used when a client wishes for a predominantly glass building envelope. Framing members may be fabricated in a shop environment, but installation and glazing is typically performed on site. Due to the continuity of the stick curtain members, the transoms and mullions are detailed such that all movement must be accommodated between the glass and the frame. A gap is provided between the glazing and the frame to allow relative movement as specified in the NZ standard NZS4223.1 [10]. In contrast, curtain walls typically use a combination of this technique, as well as seismic joints within the transoms and seismic head joints with the structure [11]. Examples of glazing with typical connection details are shown in Figures 2 and 3, respectively. 


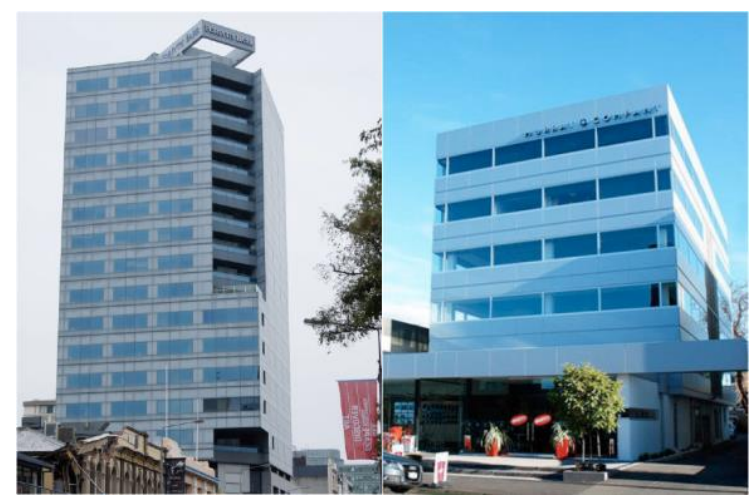

(a)

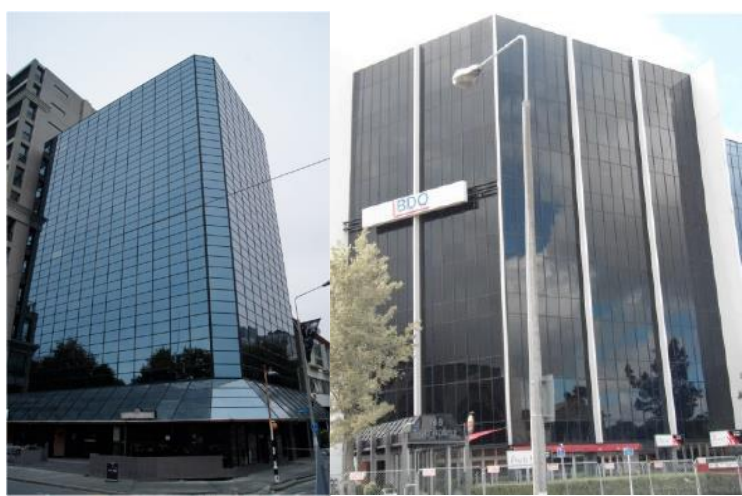

(b)

Figure 2: Typical example of glazing cladding systems [1]; (a) curtain wall, and (b) stick curtain.
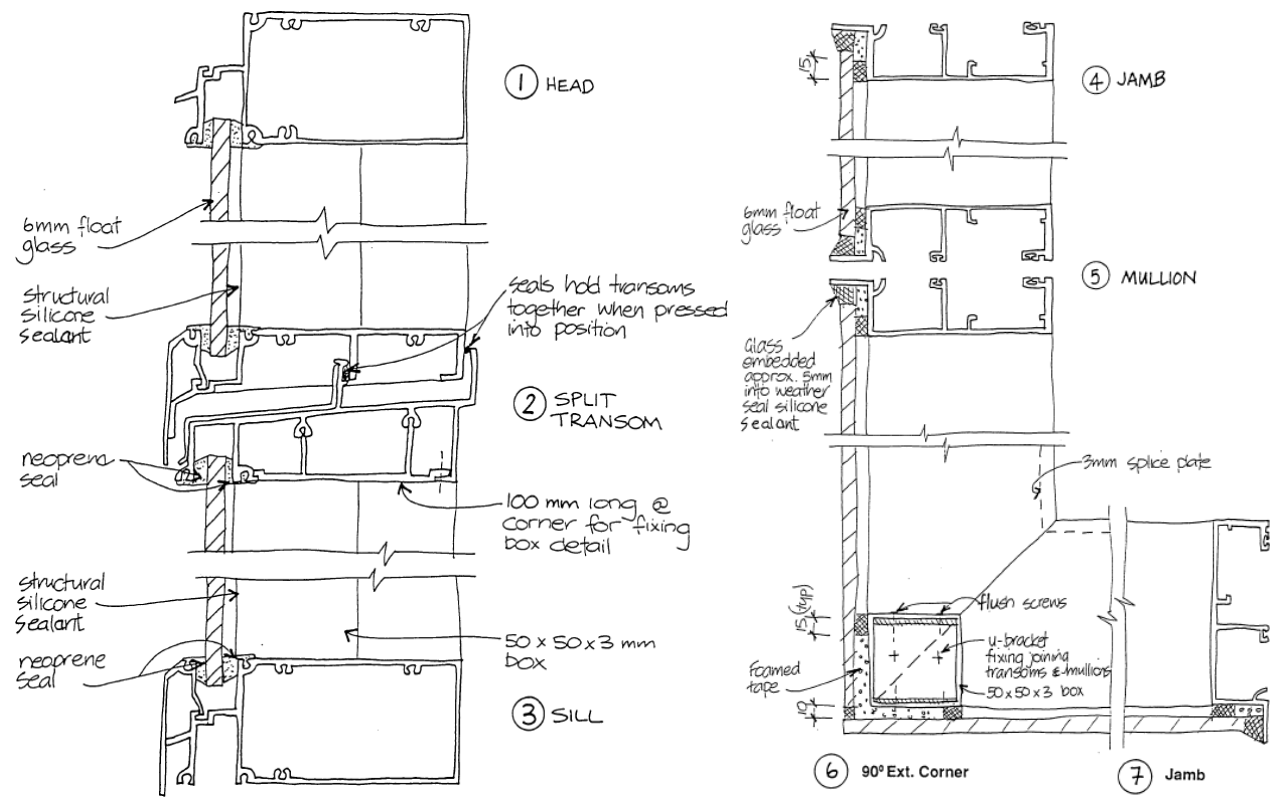

Figure 3: Typical glazing connection detail [12].

\section{Masonry Veneer}

Timber frame houses are the most common construction in New Zealand, which are most typically cladded with weatherboard followed by brick veneer. Typically, they are built with a thin air cavity between the external veneer and the inner sheathing, which functions as a drainage plane to allow any water that has penetrated the veneer to drain to the bottom of the cavity, where it encounters flashing and is directed to the outside through weep holes, rather than entering the building. Masonry veneers are only suitable for low-rise construction since they support their own weight at the ground level [1]. They have low out-ofplane strength; hence they require horizontal ties to the structure to provide out-of-plane restraint against wind and earthquake loads. Brick ties are used for this purpose, which may take the form of corrugated metal straps nailed or screwed to the structural framing, or as wire extensions to horizontal joint reinforcement in a solid masonry veneer or cavity wall. Masonry veneer cladding systems with typical connection details are shown in Figures 4 and 5.
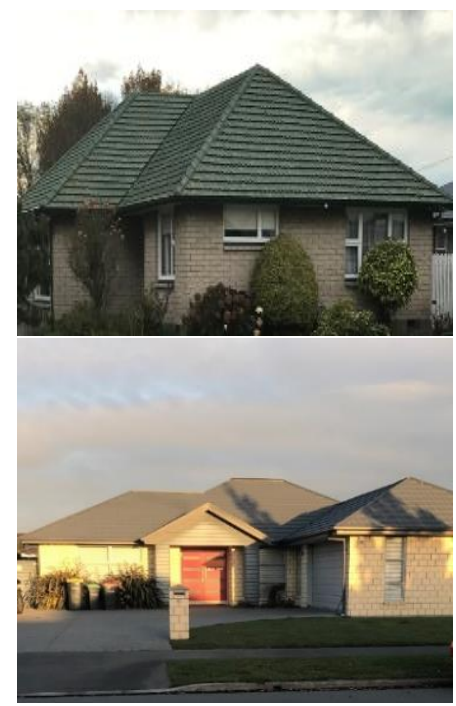

Figure 4: Typical example of masonry veneer cladding system. 


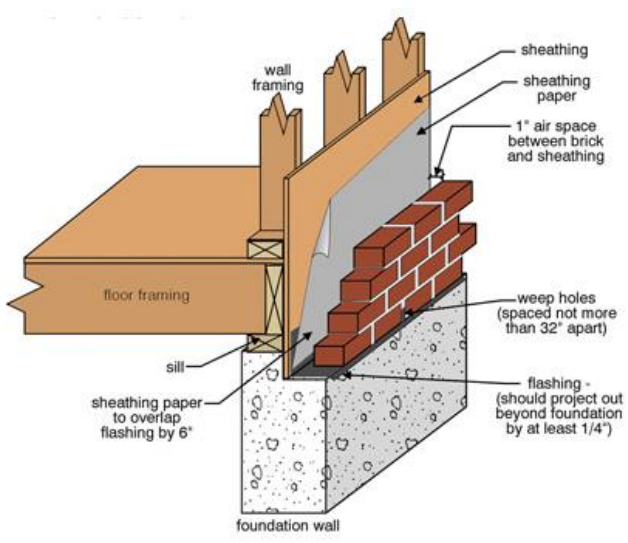

(a)

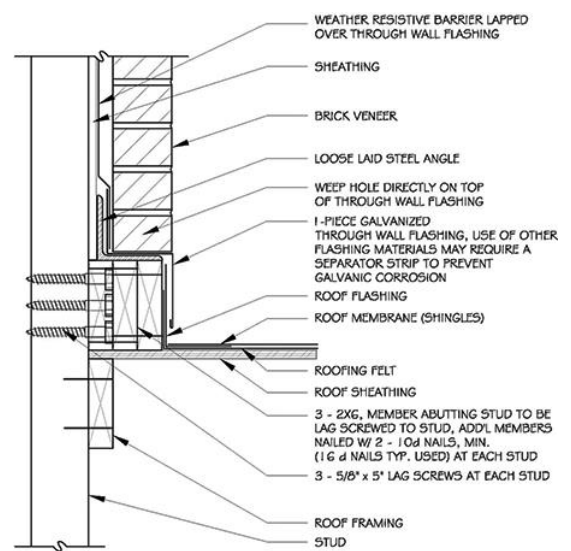

(b)

Figure 5: Masonry veneer cladding system; (a) connection [13], and (b) tie screw [14].

\section{Monolithic Cladding}

The monolithic cladding system typically consists of a sandcement plaster applied over metal lath reinforcing on a rigid or non-rigid backing material [1]. The total system has either two or three coats, and it is finished with a layer of acrylic coating to make the cladding watertight. Uncoated plaster edges are very absorbent, and will also wick water from adjacent surfaces. The watertight performance is totally reliant upon the exterior coating system creating a face seal that is impervious to moisture. Monolithic cladding is brittle and cannot accommodate movement well; thereby making it vulnerable to cracking. Movement control joints are incorporated into the cladding to address this. Any faults in the cladding such as cracks in the plaster require immediate repair to ensure the system remains watertight. Monolithic cladding systems and a typical connection detail are shown in Figure 6.
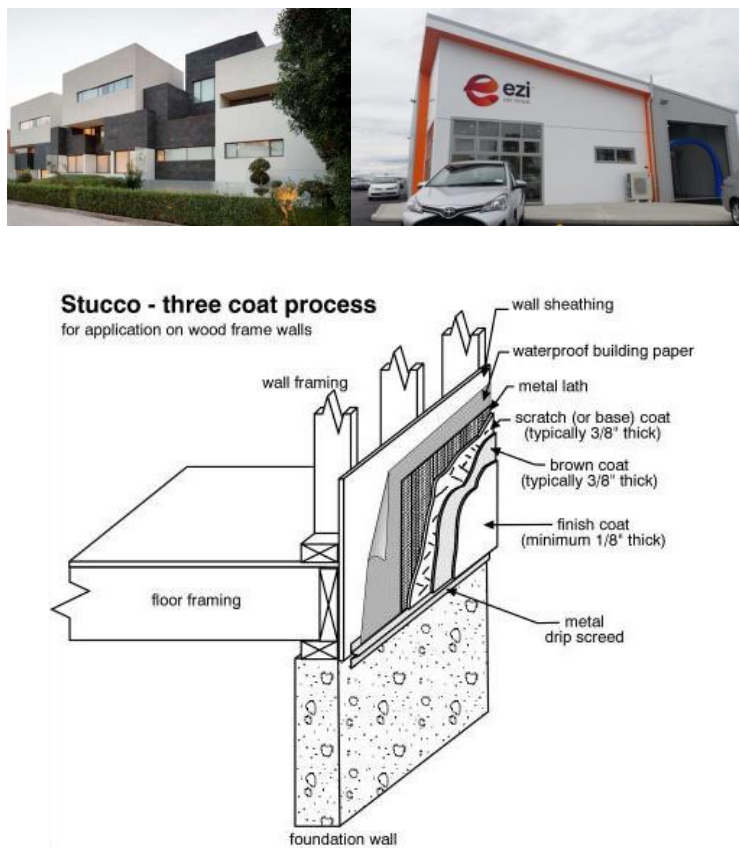

Figure 6: Monolithic cladding system with typical connection detail [15].

\section{Precast Panels}

Precast concrete panels have been the most popular cladding material in new non-residential buildings in New Zealand over the past decade [4]. The cladding system for a building may use different shapes and sizes of panels to create different architectural details. They are designed to resist wind forces and seismic forces generated from the panel self-weight [1]. Structural movement is accommodated in precast cladding systems through the connections of the panel to the structure and joints between panels [16]. Precast panel cladding systems and a typical connection detail are shown in Figure 7. Note that the tube spacer is not typically used in NZ buildings, but the fragility functions for the precast cladding system used in this study is sourced from Baird's PhD Thesis [1] on NZ cladding systems where he proposed a variation to the connection by placing a tubular spacer between the washers and by tightening the two washers against the tube.
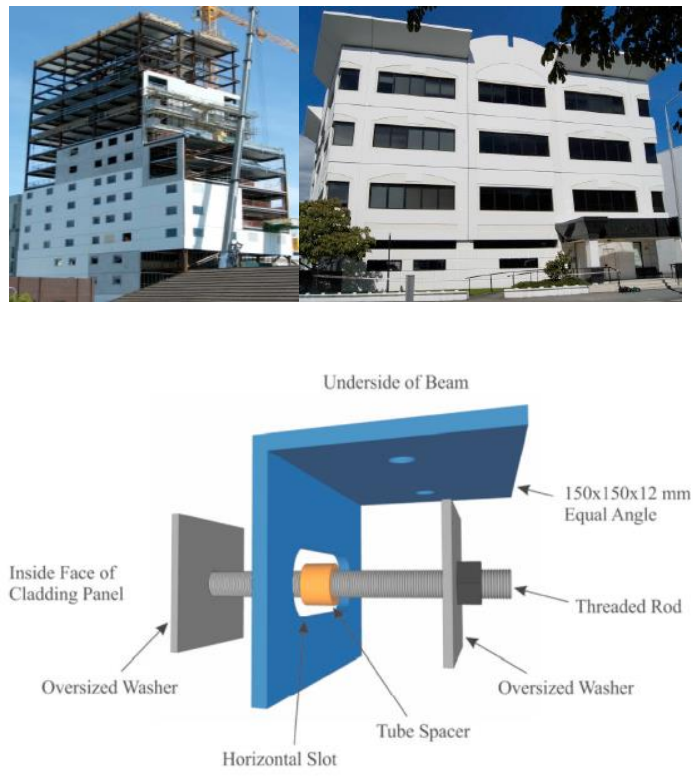

Figure 7: Precast cladding system with typical connection detail [1]. 


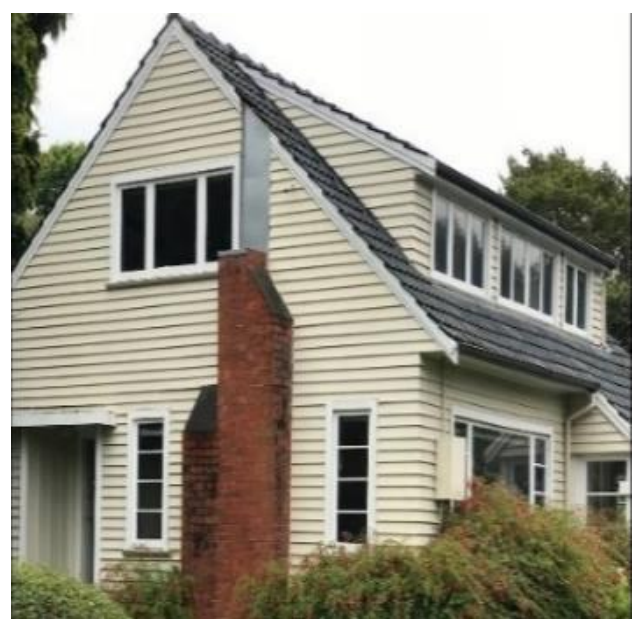

(a)

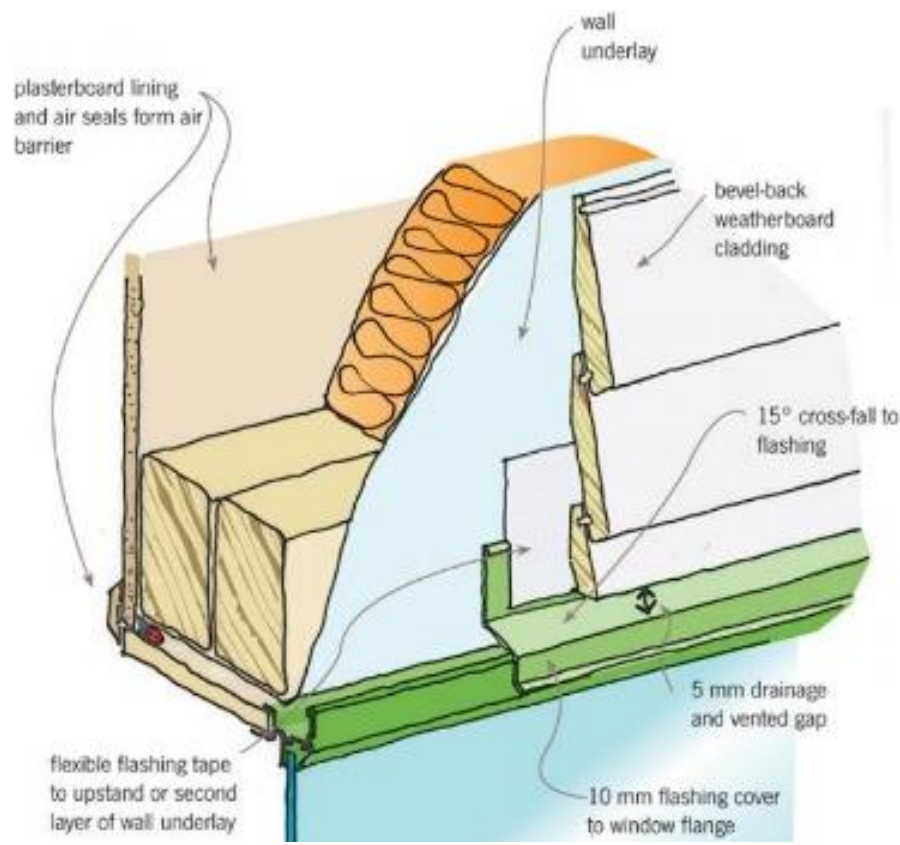

(b)

Figure 8: Lightweight cladding system; (a) residential, and (b) typical connection detail [17].

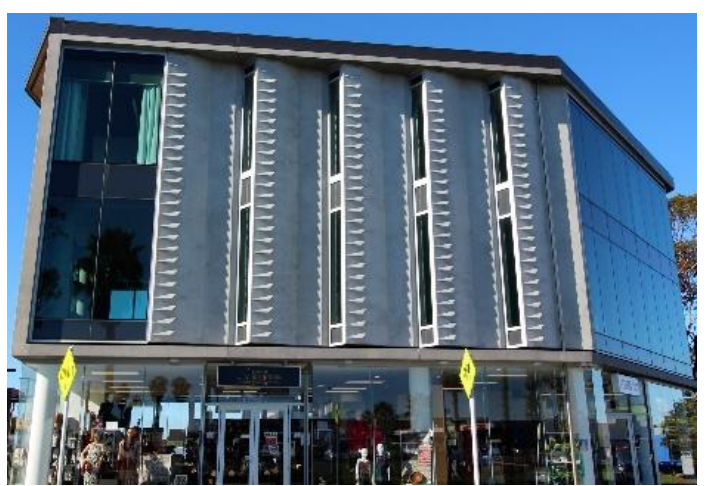

(a)

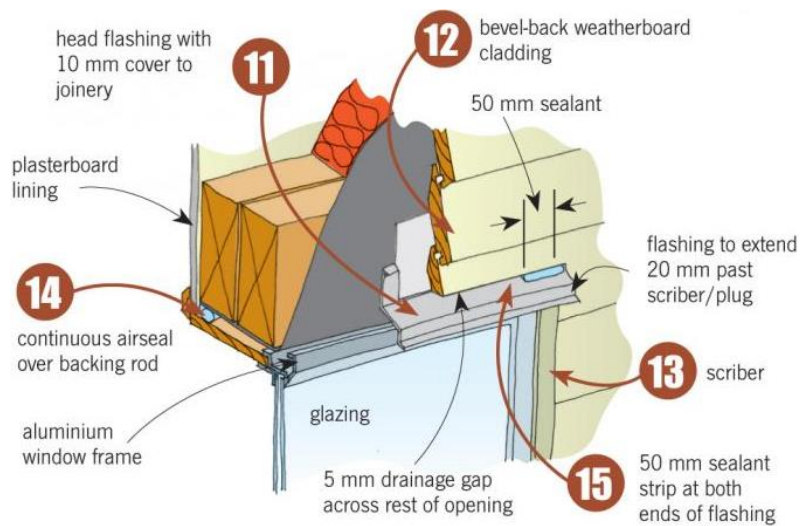

(b)

Figure 9: Lightweight cladding system; (a) commercial [18], and (b) typical connection detail.

\section{Lightweight Panels}

From an economic point of view, lightweight panel cladding systems are popular cladding choice for low-rise commercial, residential and industrial structures [1]. Lightweight panels can be simple metal sheets, plywood, insulated panels (or sandwich panels), Autoclaved Aerated Concrete (AAC), and compressed cement panels. Lightweight panel cladding systems and typical connection details for residential and commercial buildings are shown in Figures 8 and 9, respectively.

\section{COMPONENT CONTRIBUTION FUNCTIONS}

\section{Definition and Use of Contribution Functions}

The term "contribution functions" is proposed in this paper to describe relationships that link building response directly to the contribution of the component repair costs to the total storeylevel repair costs. These functions already combine quantity distributions, fragility functions, and loss functions together, and are normalized by the storey replacement cost. Therefore, these can be simply combined together to estimate the storeylevel repair cost. Examples of contribution functions can be seen on the right-side of Figure 10.

Contribution functions are separated into four groups; (i) structural (e.g. beams and columns), (ii) non-structural driftsensitive (e.g. partitions and cladding), (iii) non-structural acceleration-sensitive components located on the floor (e.g. furniture), and (iv) non-structural acceleration-sensitive components located overhead (e.g. ceiling and services). The first two groups are related to the peak interstorey drift at the storey of interest $(I D S, i)$, the third is related to the peak total floor acceleration of the floor below $(A F T, i)$, and the fourth is related to the peak total floor acceleration of the floor above $(A F T, i+1)$. These building responses are shown on the left-side of Figure 10.

The storey loss as a fraction of storey value, $l s$, can be calculated as shown in Equation 1: 

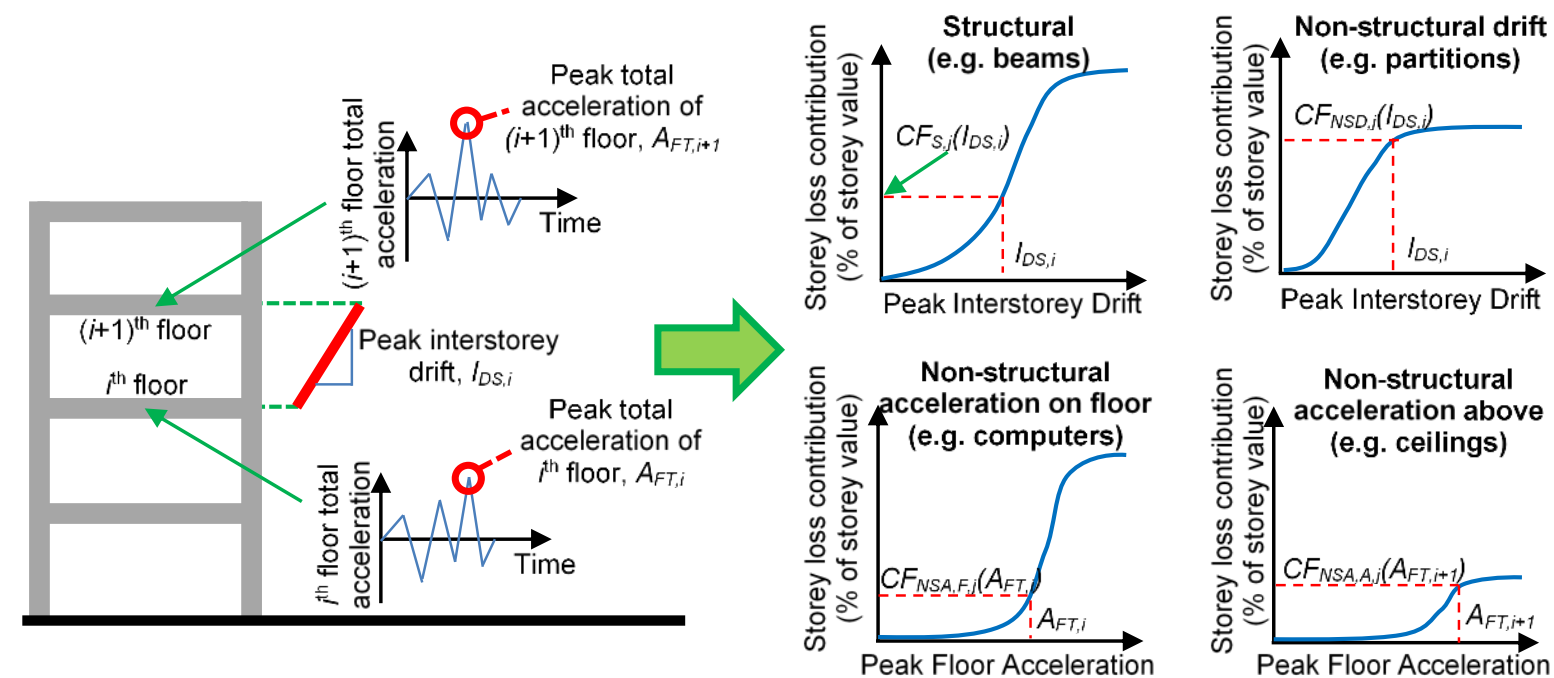

Figure 10: Application of contribution functions for rapid loss estimation.

$$
\begin{gathered}
l_{S}=\sum_{j=1}^{N_{N S A, F}} C F_{N S A, F, j}\left(A_{F T, i}\right)+\sum_{j=1}^{N_{N S A, A}} C F_{N S A, A, j}\left(A_{F T, i+1}\right) \\
+\sum_{j=1}^{N_{S}} C F_{S, j}\left(I_{D S, i}\right)+\sum_{j=1}^{N_{N S D}} C F_{N S D, j}\left(I_{D S, i}\right)
\end{gathered}
$$

where, $C F$ are the contribution functions, $N$ is the number of component types, and subscripts $S, N S D, N S A, F$, and $N S A, A$ are used for structural components, non-structural drift-sensitive components, non-structural acceleration-sensitive components on floor, and non-structural acceleration-sensitive components above, respectively.

The total building loss, $L_{\text {Total }}$, expressed as a fraction of total building value can be calculated following Equation 2:

$L_{\text {Total }}=\sum_{S=1}^{N_{\text {storey }}}\left(l_{s} \cdot a_{s}\right) / \sum_{S=1}^{N_{\text {storey }}} a_{S}$

where, $a_{S}$ is the floor area of the $S^{\text {th }}$ storey level, and $N_{\text {storey }}$ is the total number of storey.

\section{Overview of Studies Related to Development of Contribution Functions}

One of the earlier concepts of performing seismic loss estimation at a storey level was proposed by Aslani and Miranda [19]. Here, the expected loss due to a component at floor level for a given value of Engineering Demand Parameter $(E D P)\left(E\left[L_{C \mid E D P}\right]\right)$ is calculated deterministically following Equation 3:

$E\left[L_{C \mid E D P}\right]=A_{C} \times \sum_{i=1}^{n_{D S}} P\left(D_{i} \mid E D P\right) \times E\left[l_{C \mid D_{i}}\right]$

where, $A_{C}$ is the total area/number of the component on the storey of interest; $E\left[l_{C \mid D i}\right]$ is the expected repair cost per unit area of the component for the damage state $D_{i} ; n_{D S}$ is the number of discrete damage states considered in the component fragility; and $P\left(D_{i} \mid E D P\right)$ is the probability of damage being in the $i^{\text {th }}$ damage state for a given $E D P$ value (say $e d p$ ). Here, $l_{C \mid D i}$ are generated using the assigned probability distributions based on the collected data, whereas $P\left(D_{i} \mid E D P\right)$ can be computed from the fragility functions following Equation 4:

$$
\begin{gathered}
P\left(D_{i} \mid E D P=e d p\right) \\
=\Phi\left(\ln \left(\frac{e d p}{x_{m, i}}\right) / \beta_{i}\right)-\Phi\left(\ln \left(\frac{e d p}{x_{m, i+1}}\right) / \beta_{i+1}\right) \\
\text { for } i \neq n_{D S} \\
P\left(D_{i} \mid E D P=e d p\right)=\Phi\left(\ln \left(\frac{e d p}{x_{m, i}}\right) / \beta_{i}\right) \\
\text { for } i=n_{D S}
\end{gathered}
$$

where, $x_{m, i}$ and $\beta_{i}$ are the logarithmic mean and dispersion of the component's capacity to resist $i^{\text {th }}$ damage state, respectively; and $\Phi()$ is the standard normal cumulative distribution function.

Dhakal et al. [9] extended this methodology to account for (i) uncertainty in the repair cost values rather than using an expected value approach, and (ii) variation in quantity distribution. They have previously proposed a framework to develop contribution functions for interior drywall partitions and suspended ceilings. In this approach, a Monte Carlo simulation is performed to consider the variation in both component density and $l_{c r \mid D i}$. The total component repair cost for a single Monte Carlo simulation trial can be obtained following Equation 5:

$$
\begin{aligned}
L_{C \mid E D P}= & P\left(D_{1} \mid E D P\right) \times l_{c r \mid D_{1}}+P\left(D_{2} \mid E D P\right) \times l_{c r \mid D_{2}}+ \\
& \ldots \ldots \ldots+P\left(D_{n} \mid E D P\right) \times l_{c r \mid D_{n}}
\end{aligned}
$$

where, $l_{c r \mid D i}$ is the random variable of unit cost of repairing or replacing a component damaged to the $i^{\text {th }}$ damage state. The total unit cost of component repair/replacement is then multiplied by the component density factor to convert the per unit component repair cost to repair cost per unit floor area. An example of this for dry wall partitions [9] is shown in Equation 6:

$\bar{L}_{P \mid I D R}=L_{P \mid I D R} \times R_{P} \times H_{P}$ 
where, $\bar{L}_{P \mid I D R}$ is the expected loss due to partition damage per square metre of floor area at a given drift level; $L_{P \mid I D R}$ is the loss per unit partition area; $R_{P}$ is the random realisation of the partition density function (length per unit floor area); and $H_{P}$ is the average partition wall height. Depending on the component, the density function can be expressed in terms of area, length or weight.

Inherent variations in critical parameters such as building regularity, geometry/layout, orientations, ground condition and actual earthquake input are considered in the structural analysis. Uncertainties in these parameters are hence not propagated in the development of the loss contribution functions where the result of structural analysis $(e d p)$ is taken as input.
A summary of the overall framework for developing contribution functions is shown in Figure 11. During a single trial of calculation a random inter-storey drift ratio is generated first and the probability of each damage state is calculated next by using Equation 4 above. Then, the repair or replacement costs corresponding to the different damage states are obtained from the idealized distribution curves of the costs. In order to consider all probable variations, several trials of simulations are run by using Equation 5 for each drift ratio. Afterwards, the randomly selected quantity distribution is combined as per Equation 6.

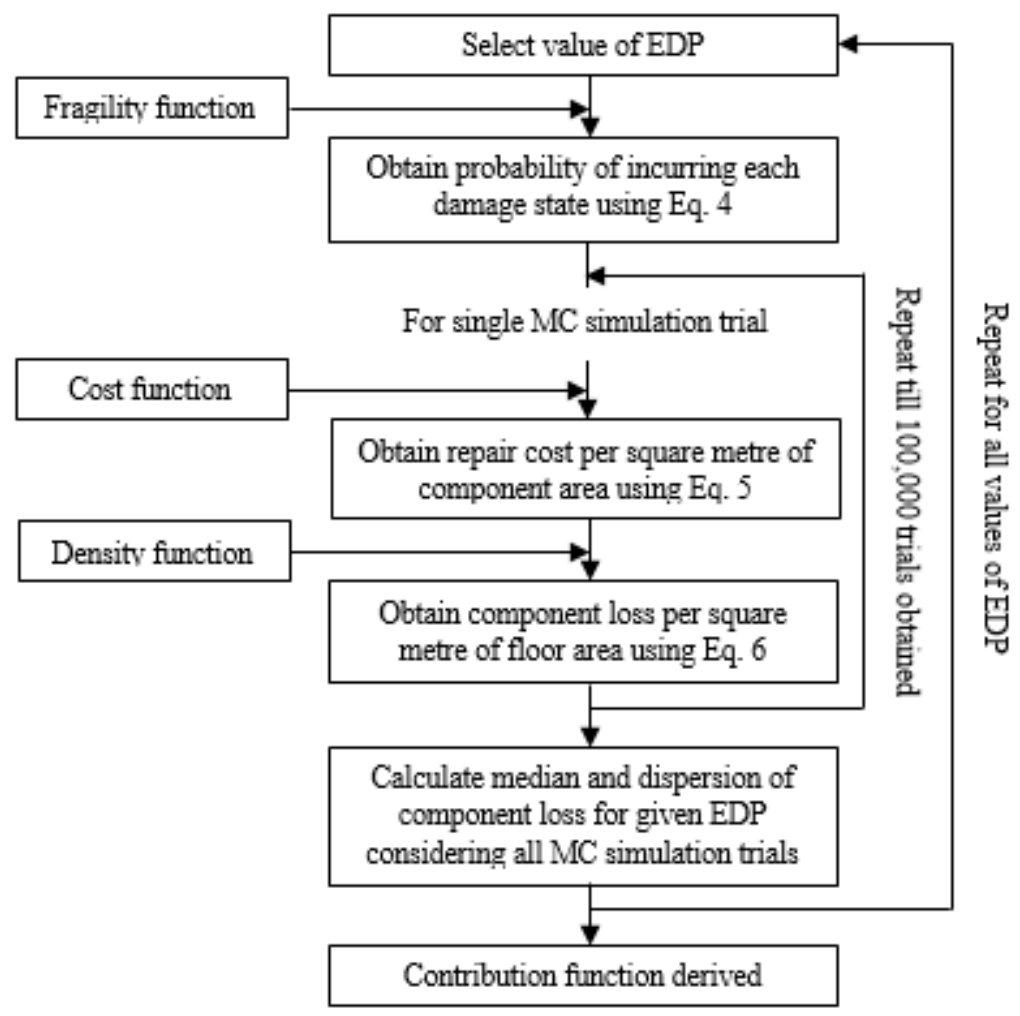

Figure 11: Overall framework for developing contribution functions.

\section{METHODOLOGY}

To develop the cladding contribution function as described in the previous section, the following steps were carried out:

- Field surveys of buildings were done to obtain information on typical cladding types, quantity, and building dimensions.

- $\quad$ Survey data were processed to identify the most common types of cladding and develop probabilistic distribution of cladding length to floor area ratio $\left(R_{C L}\right)$ in residential, commercial and industrial buildings.

- Suitable fragility functions for each types of cladding were identified and selected from literature.

- Repair/replacement cost for each cladding type under different damage states were obtained from interviews with consultants, suppliers and builders or from literature.

- Monte Carlo simulations were performed with inputs from previous steps to develop contribution functions.

In the first step, a building survey is performed in Christchurch, New Zealand for residential, commercial and industrial buildings. The survey data was then used to identify the most common types of claddings used and cladding length to floor area ratio.
The next step is to source the fragility functions for different types of claddings by reviewing literature corresponding to the identified and classified cladding types. The details of the selected fragility functions are described later in the paper.

The next step is to obtain the repair/replacement costs for different types of claddings corresponding to each cladding type and associated damage states. The collection of repair costs for different cladding systems is described in detail in later sections. The repair cost per unit area of the cladding panel, $L_{C L \mid D i}$ are generated using the assigned probability distributions based on damage states identified from fragility functions.

In the last step, Monte Carlo simulation is used to generate the contribution functions for different types of cladding by coding a script in MATLAB. The input of random variables for the simulation include the probability of being in a damage state at a given engineering demand parameter (inter-storey drift ratio), repair costs, and the cladding length per floor area as shown in Figure 11.

The expected seismic loss per square metre of the cladding panel, $L_{C L \mid I D R}$, considering the probability and consequence of different damage states (i.e. $D S_{1}, D S_{2}, D S_{3} \ldots D S_{n}$ ), can be written as, 


$$
\begin{aligned}
L_{C L \mid I D R}= & P\left(D_{1} \mid I D R\right) \times l_{C L r \mid D_{1}}+P\left(D_{2} \mid I D R\right) \times l_{C L r \mid D_{2}} \\
& +\cdots \ldots \ldots+P\left(D_{n} \mid I D R\right) \times l_{C L r \mid D_{n}}
\end{aligned}
$$

where, $P\left(D_{i} \mid I D R\right)$ is the probability of the $i^{\text {th }}$ damage state at a particular Inter-storey Drift Ratio (IDR), and $l_{C L r \mid D i}$ is the random realisation of unit cost of repairing or replacing a cladding panel corresponding to the $i^{\text {th }}$ damage state. Cladding loss in terms of percentage of complete replacement cost, $L_{C L \_r e p \mid I D R}$ can be calculated as,

$L_{C L_{-} r e p \mid I D R}=\frac{L_{C L \mid I D R}}{L_{C L \mid D_{n}}} \times 100$

So far, seismic loss has been calculated per square metre of the cladding panel. To determine the contribution of the cladding damage in total seismic loss of a building, the distribution of the cladding length has to be combined with the cladding loss as,

$\bar{L}_{C L \mid I D R}=L_{C L \mid I D R} \times R_{C L} \times H_{C L}$

where, $\bar{L}_{C L \mid I D R}$ is the expected loss due to cladding damage per square metre of floor area at a given drift level. In this study, the height of the cladding panel, $H_{C L}$ is considered constant as $2.7 \mathrm{~m}$ for residential buildings and $3.5 \mathrm{~m}$ for commercial and industrial buildings.

\section{BUILDING SURVEY RESULTS}

\section{Common Cladding Systems}

To identify the common types of cladding used in varying building usage, together with their distribution, an intensive survey was performed in and around Christchurch city for residential, commercial, and industrial buildings. Building usage, dimensions, cladding type and cladding length (after deducting the area taken by windows and doors) were recorded from the building survey. The dimension of the buildings was determined by using Google Earth images, by field estimation, or by examining architectural and structural drawings. The survey data was analysed to identify the most common types of claddings used and the cladding length to floor area ratio. Cladding types were recorded for a large number of random samples of residential buildings from different locations in Christchurch, which are representative of both older and newer construction. To ascertain the adequacy of the collected data size, a sensitivity analysis was performed by adding a number of new random data entries. When the proportions of different cladding types did not noticeably change, despite additional random data entries, it was decided that the increased sample size is representative of the entire residential building stock in Christchurch. Similar sensitivity analyses were repeated for commercial and industrial buildings as well. The cladding distribution data collected from the field survey is presented in Appendix A.

From the field survey, residential buildings were observed to have a single type of cladding throughout the perimeter of the building whereas commercial and industrial buildings were observed to have a mixed use of different types of cladding in a single building. The proportions of different cladding types in residential, commercial, and industrial buildings deduced from the survey data are presented in Figure 12. Here, total length of an individual cladding system (e.g. masonry veneer) is presented as the percentage of the cumulative total lengths of different cladding systems of all buildings of a particular use (e.g. residential). Analysis of 100 data shows that masonry veneer, monolithic cladding, and lightweight panels are the most common types of cladding systems used in residential buildings as shown in Figure 12a. Figure 12b, generated from 63 random data, shows that glazing, lightweight panels, and precast panels are the three most common types of cladding systems used in commercial buildings. Similarly, lightweight panels, monolithic cladding, and precast panels are the three most common types of cladding systems used in industrial buildings as per the survey results of 35 sample data presented in Figure 12c.

Discussions with contractors indicated that lightweight panels often do not incur significant damage during earthquakes due to their increased flexibility and decreased weight. Based on this and the findings from the survey, the rest of this paper will focus on glazing, masonry veneer, monolithic, and precast panels cladding systems.

- Masonry "Monolithic "Lightweight "Glazing "Precast

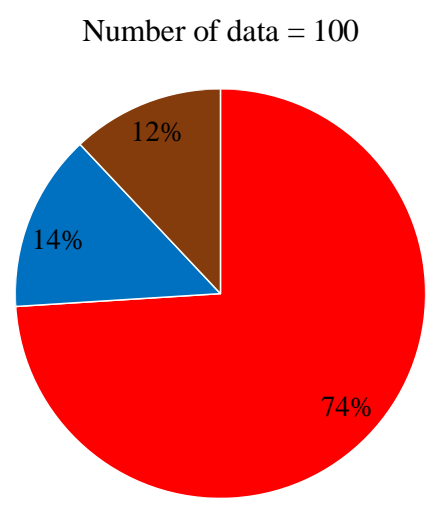

(a)

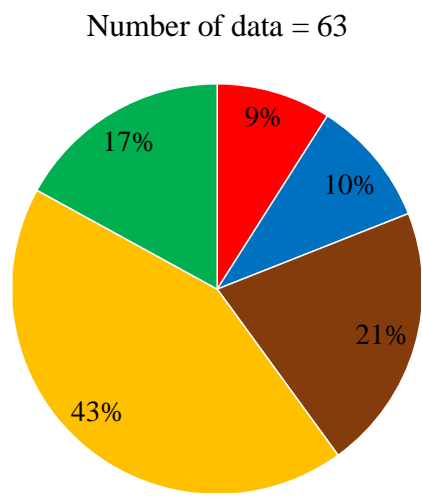

(b)

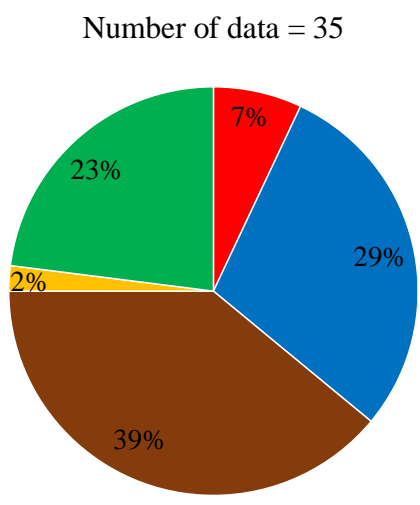

(c)

Figure 12: Common cladding systems; (a) residential, (b) commercial, and (c) industrial.

\section{Cladding Density Functions: Distribution of Cladding Systems in Different Building Types}

After identifying the common types of cladding, the same survey data were analysed to get the distribution of cladding length- to-floor area ratio for residential, commercial, and industrial buildings as shown in Figure 13. These distributions of cladding length consider all types of claddings present in an individual building category. For all three types of buildings, an empirical distribution based on the actual data and a lognormal 
distribution fit were plotted. A goodness-of-fit test [20], performed on the fitted distributions to the collected data, shows better fitting with lognormal distribution compared to normal distribution. From the cladding distribution, it is found that residential buildings have greater proportion of mean cladding length in comparison to commercial and industrial buildings. This may be because industrial buildings have relatively large openings to allow access for trucks and heavy equipment.

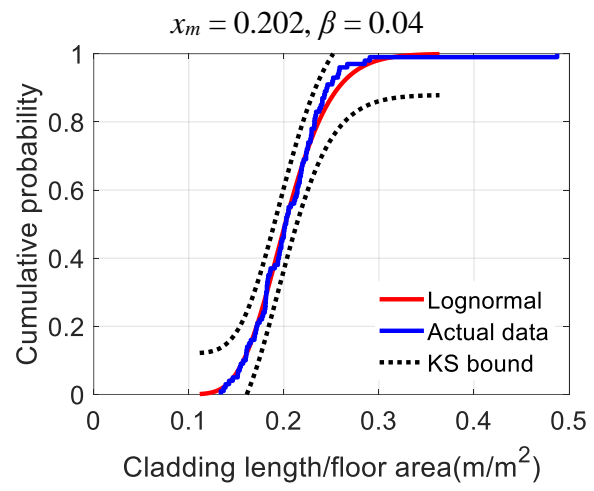

(a)

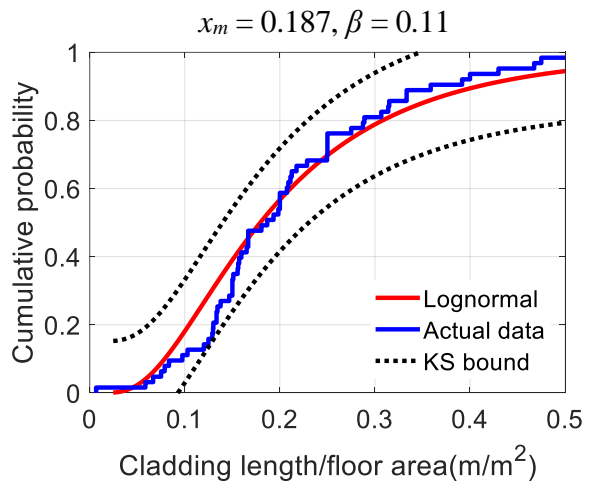

(b)

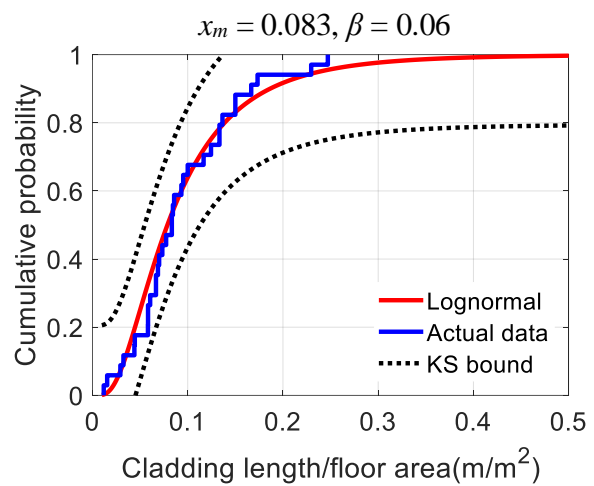

(c)

Figure 13: Cladding density functions for different building usage; (a) residential, (b) commercial, and (c) industrial.

\section{FRAGILITY FUNCTIONS FOR CLADDING SYSTEMS}

Claddings are unique non-structural components in the sense that their seismic performance depends on both drift and acceleration. The in-plane performance of a cladding depends on the average drift within the connections between the cladding and the structural system: whereas the out-of-plane performance of a cladding depends on the acceleration of the panel, which induces inertial force on the connections. Hence, for a given cladding type, the seismic performance of a cladding system, and its fragility functions, depend on the type and configuration of the connection between the cladding and the structural system. However, development of new fragility functions for different configurations of the connections between the claddings and the structural systems is out of scope of this study. Therefore, fragility functions are sourced from literature for cladding types with connection details similar to NZ construction. For connection details significantly different from the tested claddings based on which the fragility functions are generated herein, the contribution functions developed in this study are not readily applicable and will need to be adjusted.

\section{Glazing}

The fragility function for glazing is taken from O'Brien et al. [21] which is based on the experimental works carried out on six specimens of $6^{*} 5$ feet glass panel used in mid-rise curtain wall system. The connection details used in this glazing type is similar to the New Zealand mid-rise curtain wall system. Hence, herein the adopted fragility function is applicable to New Zealand. The pictures of typical damages for glazing are presented in Figure 14.

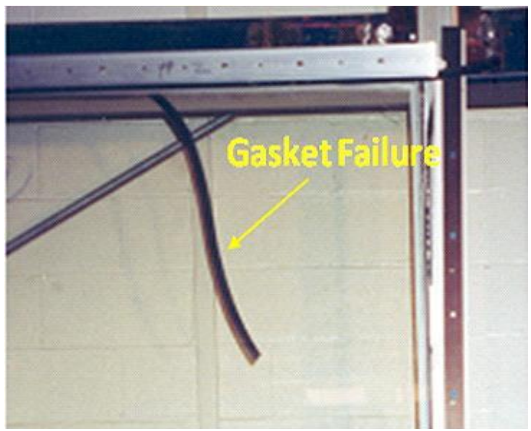

(a)

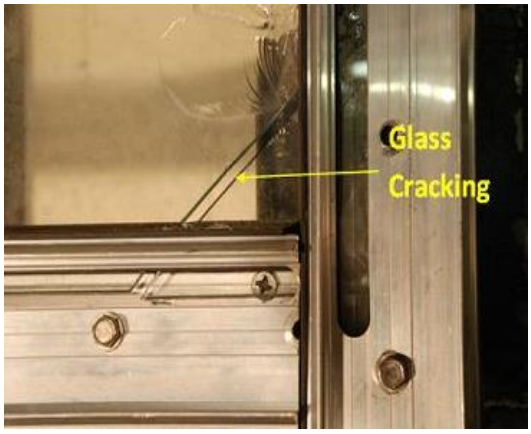

(b)

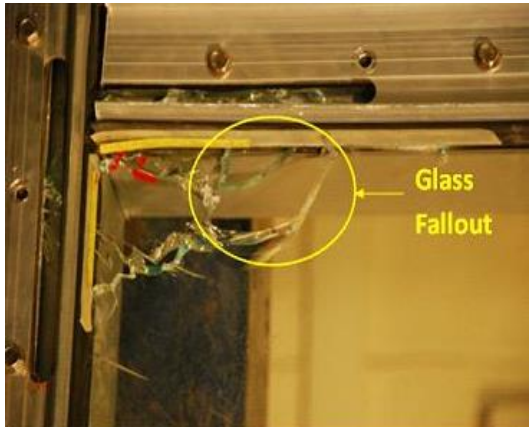

(c)

Figure 14: Observed glazing damages [21]; (a) gasket failure, (b) glass cracking, and (c) glass fallout.

Gasket failure and glass cracking are less severe damage states that govern the serviceability of the building but these damage states do not pose an immediate life safety hazard. However, the final damage state; i.e. glass fallout, is a failure mode which 
can result in a life-safety hazard. The fragility curve parameters along with the description of these three damage states are presented in Table 1. Fragility curves generated from these parameters are also shown in Figure 15.

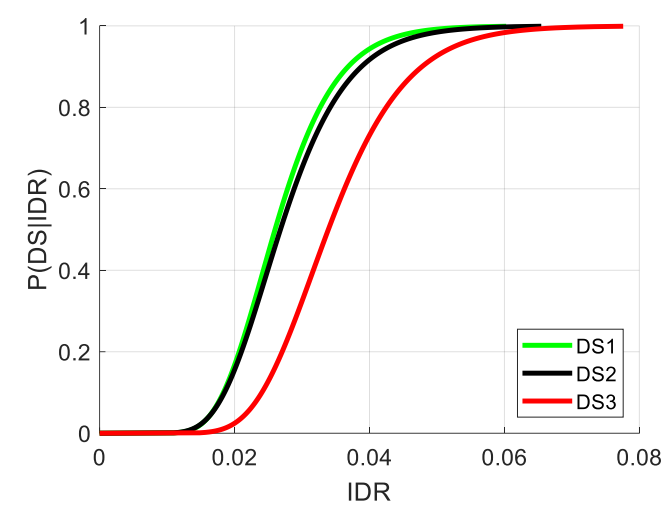

Figure 15: Glazing fragility function.

Table 1: Fragility curve parameters for glazing [21].

\begin{tabular}{cccc} 
Damage Level & Description & $\boldsymbol{x}_{\boldsymbol{m}}$ & $\boldsymbol{\beta}$ \\
\hline DS1 & Gasket failure & 0.0260 & 0.272 \\
DS2 & Glass cracking & 0.0268 & 0.289 \\
DS3 & Glass fallout & 0.0339 & 0.268 \\
\hline
\end{tabular}

\section{Masonry Veneer}

The fragility function for masonry veneer cladding is taken from Petry and Beyer [22] which is based on the experimental works carried out in unreinforced clay brick masonry walls. Here, masonry veneer walls are damaged since their connections to the supporting structure are stiff enough to transfer the drift of the structural system to the walls. Brick ties need to be screwed into the timber frame in modern construction, herein the adopted fragility function is applicable to New Zealand. Damage states defined for masonry veneer cladding based on experimental observations are presented in Figure 16 .

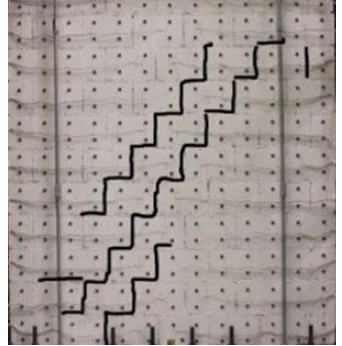

(a)

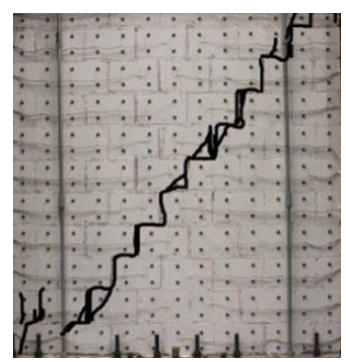

(c)

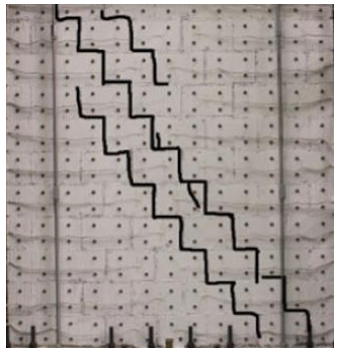

(b)

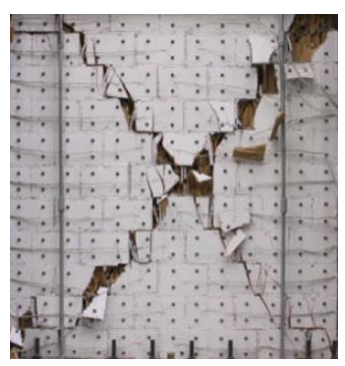

(d)
Figure 16: Observed damages to masonry veneer [22]; (a) stair step crack, (b) crack propagates through brick, (c) concentration in diagonal crack, and (d) shearing-off of corners.
Table 2: Fragility curve parameters for masonry veneer cladding [22].

\begin{tabular}{cccc} 
Damage Level & Description & $\boldsymbol{x}_{\boldsymbol{m}}$ & $\boldsymbol{\beta}$ \\
\hline DS1 & $\begin{array}{c}\text { Stair step crack visible } \\
\text { Crack propagates } \\
\text { through brick }\end{array}$ & 0.0015 & 0.4 \\
DS2 & $\begin{array}{c}\text { Concentration in } \\
\text { diagonal crack }\end{array}$ & 0.0035 & 0.4 \\
DS3 & Shearing-off of corners & 0.006 & 0.4 \\
DS4 & & & 0.4 \\
\hline
\end{tabular}

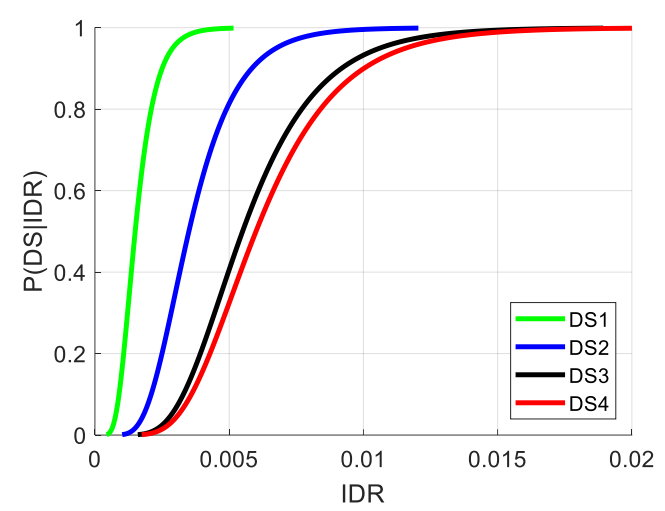

Figure 17: Masonry fragility function.

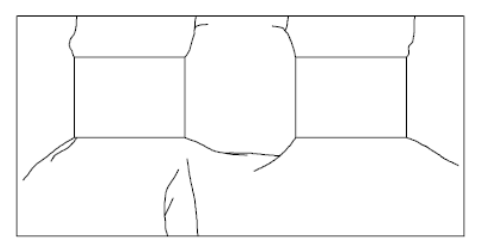

(a)

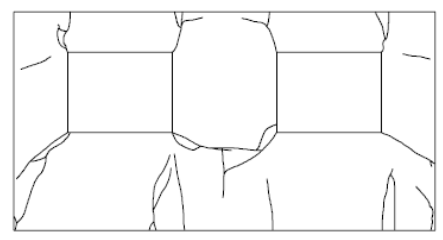

(b)

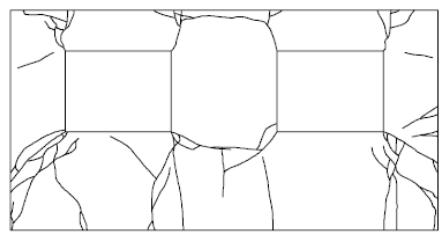

(c)

Figure 18: Observed damages to monolithic cladding systems [23]; (a) hairline cracks, (b) extension of cracks, and (c) branching of cracks.

The fragility curve parameters along with description of damage states are presented in Table 2, and the fragility curves generated from these parameters are shown in Figure 17.

\section{Monolithic Cladding}

The fragility function for monolithic cladding is taken from Arnold et al. [23] which is based on the experimental works carried out on stucco and gypsum sheathed walls. Stucco, EIFS, and Harditex are three different monolithic cladding systems used in New Zealand construction. Herein, the adopted fragility 
function is applicable to stucco that is common in older construction. Pictures of observed damages for monolithic cladding are presented in Figure 18.

The fragility curve parameters, along with description of damage states, are presented in Table 3 , and the fragility curves generated from these parameters are shown in Figure 19.

\section{Table 3: Fragility curve parameters for monolithic cladding} [23].

\begin{tabular}{cccc} 
Damage Level & Description & $\boldsymbol{x}_{\boldsymbol{m}}$ & $\boldsymbol{\beta}$ \\
\hline DS1 & Hairline cracks & 0.002 & 0.4 \\
DS2 & Extension of cracks & 0.004 & 0.4 \\
DS3 & Branching of cracks & 0.007 & 0.4 \\
\hline
\end{tabular}

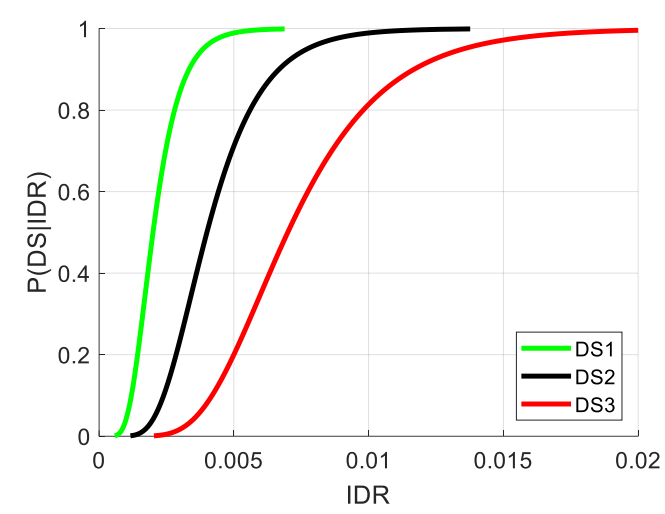

Figure 19: Monolithic fragility function.

\section{Precast Concrete Cladding}

The fragility function for precast concrete cladding is taken from Baird [1] which is based on the experimental works carried out in precast cladding panels. Common connection types to the precast concrete cladding panel are bearing, tieback, slotted, fixed and dissipative. Herein adopted fragility function is only applicable to slotted connection. Pictures of observed damages for precast concrete cladding are presented in Figure 20.

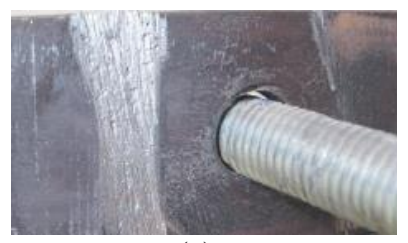

(a)

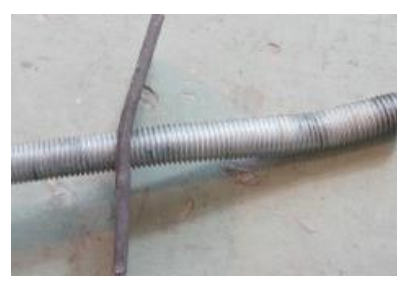

(b)

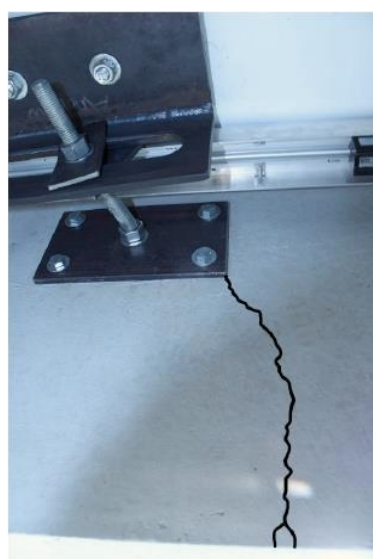

(c)
Figure 20: Observed damage to precast [1]; (a) galling of washer, (b) bending of washer and bolt, and (c) crack in cladding panel.

Precast panels are likely to be damaged in seismic events if their connections to the supporting structure are stiff enough to transfer the drift of the structural system to the panels, but Baird [1] found that for the typical precast panel connection details used in NZ the connections are likely to incur greater damage.
Here, fragility functions are developed based on experimental testing of slotted connections in which the ultimate failure performance level (DS4) was not tested. The extent of damage to slotted connections depends on the maximum lateral displacement of the connection. Since the connection at the bottom of the precast panel is fixed, the shear deformation of the precast panel is governed by the lateral displacement of the top connection. To obtain the lateral drift ratio, the lateral displacement of the top connection is divided by the distance between the top and bottom connections (which normally is the clear space between the floor slab and ceiling); thereby making the precast cladding panel drift equal to the inter-storey drift. The fragility curve parameters with description of damage states are presented in Table 4, and the corresponding fragility curves are shown in Figure 21.

\begin{tabular}{cccc} 
Table 4: Fragility curve parameters for precast concrete & \\
cladding [1]. & & & \\
Damage Level & Description & $\boldsymbol{x}_{\boldsymbol{m}}$ & $\boldsymbol{\beta}$ \\
\hline DS1 & $\begin{array}{c}\text { Galling of washer } \\
\text { Bending of washer } \\
\text { and bolt }\end{array}$ & 0.008 & 0.2 \\
DS3 & $\begin{array}{c}\text { Crack in cladding } \\
\text { panel }\end{array}$ & 0.009 & 0.2 \\
\hline
\end{tabular}

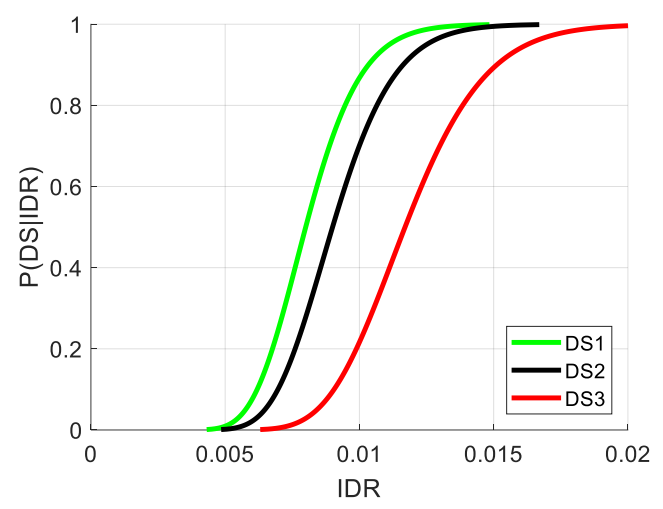

Figure 21: Precast fragility function.

\section{REPAIR COST OF CLADDING SYSTEMS}

In order to obtain the repair or replacement costs for different types of cladding damaged due to different damage states mentioned in the previous section, a number of questionnaires were sent by email to consultants, suppliers and builders with experience in designing/manufacturing/building different types of claddings. As there can be different sizes, materials and connection methods for a given category of cladding system resulting in different costs, it would be difficult for the respondents to provide a single value of repair or replacement cost. Hence, ranges of cost (rather than single values) were asked in the questions.

The questionnaires were sent to 57 companies, but most companies were unwilling to provide information about the cost of repair of the cladding. Hence, an alternate method was adopted to obtain the repair and replacement costs by communicating (face-to-face) with local builders at random construction sites, and this method was found to be more effective than sending questionnaires by email. Finally, three datasets were collected for masonry veneer cladding and four data sets were obtained for monolithic cladding, which were assumed sufficient for this study. Only one response was obtained for glazing, however, this was received from the largest commercial glazing supplier in New Zealand and is therefore deemed to be representative of most glazing repairs and new installations in commercial buildings. The 
repair/replacement costs for precast concrete were obtained from the data reported by Baird [1] with a $12.68 \%$ construction cost inflation adjustment [24]. The cladding damage repair and replacement cost data collected from the survey and face-toface communication with builders is presented in Appendix B.

In this study, the cost data range provided by each respondent is assumed to fit a normal distribution. For each data (i.e. a range of cost), the lower bound was assumed to represent the $10^{\text {th }}$ percentile and the upper bound as the $90^{\text {th }}$ percentile. All entries were given equal weightings before combining and calculating the mean and the standard deviation of the combined data. Thus derived repair/replacement costs for all types of cladding systems for different damage states are presented in Table 5.

Table 5: Repair/replacement costs for different damage states of four types of cladding.

\begin{tabular}{|c|c|c|c|}
\hline $\begin{array}{c}\text { Cladding } \\
\text { Types }\end{array}$ & $\begin{array}{l}\text { Damage } \\
\text { State }\end{array}$ & $\begin{array}{c}\text { Average } \\
\text { Repair Cost } \\
\left(\mathrm{NZ} \$ / \mathrm{m}^{2}\right)\end{array}$ & $\begin{array}{c}\text { Standard } \\
\text { Deviation } \\
\left(\mathrm{NZ} \$ \mathrm{~m}^{2}\right)\end{array}$ \\
\hline \multirow{3}{*}{ Glazing } & DS1 & 73 & 5.47 \\
\hline & DS2 & 565 & 58.59 \\
\hline & DS3 & 565 & 58.59 \\
\hline \multirow{4}{*}{ Masonry } & DS1 & 283.3 & 39.1 \\
\hline & DS2 & 375 & 29.3 \\
\hline & DS3 & 483.3 & 52.08 \\
\hline & DS4 & 608.3 & 97.66 \\
\hline \multirow{3}{*}{ Monolithic } & DS1 & 97.5 & 12.7 \\
\hline & DS2 & 775 & 136.7 \\
\hline & DS3 & 1250 & 273.4 \\
\hline \multirow{3}{*}{ Precast } & DS1 & 43.4 & 16.29 \\
\hline & DS2 & 63.8 & 24.91 \\
\hline & DS3 & 208.3 & 81.34 \\
\hline
\end{tabular}

\section{CONTRIBUTION FUNCTIONS FOR CLADDING} SYSTEMS

The data input in terms of cladding distribution (i.e. density), fragility and repair/replacement cost are combined and uncertainties within each of these functions are carried forward through 100,000 Monte Carlo simulations at each individual value of $E D P$ to develop the contribution functions for different types of cladding.

\section{Loss in Terms of Percentage of Replacement Cost}

Expected loss in terms of percentage of replacement cost for all four types of claddings are calculated using Equation 8. These are presented in Table 6 and Figure 22, which prove that masonry veneer and monolithic cladding start incurring losses at much smaller drifts compared to the other two types, especially glazing.

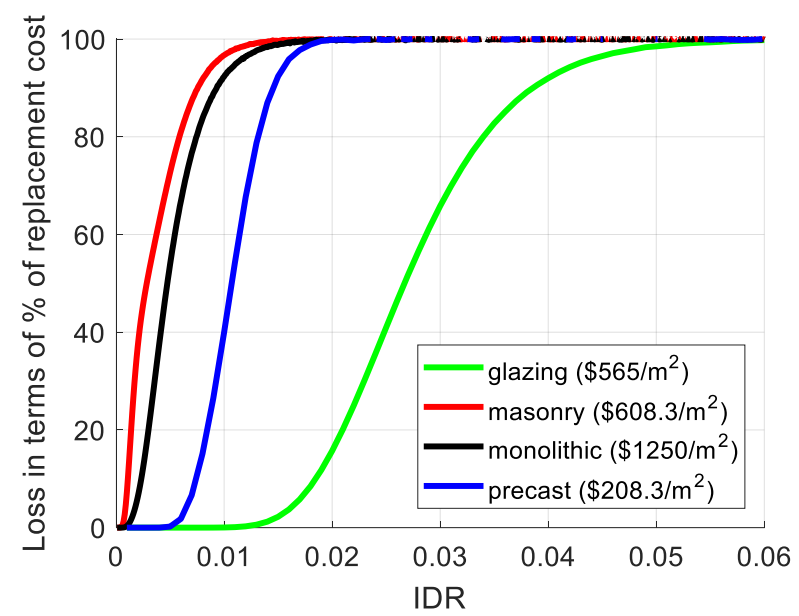

Figure 22: Comparison of percentage loss incurred by the four cladding types at different IDR.

\section{Table 6: Percentage loss of the four cladding types at different IDR.}

\begin{tabular}{ccccc} 
IDR & \multicolumn{4}{c}{ Percentage Loss } \\
& Glazing & Masonry & Monolithic & Precast \\
\hline 0.002 & 0.0 & 36.9 & 6.2 & 0.0 \\
0.004 & 0.0 & 62.8 & 37.6 & 0.0 \\
0.006 & 0.0 & 81.0 & 66.8 & 1.8 \\
0.008 & 0.0 & 91.7 & 83.7 & 15.1 \\
0.010 & 0.0 & 96.7 & 92.4 & 39.9 \\
0.012 & 0.3 & 98.7 & 96.4 & 67.7 \\
0.014 & 1.2 & 99.4 & 98.4 & 87.1 \\
0.016 & 3.7 & 99.8 & 99.2 & 95.8 \\
0.018 & 8.5 & 99.9 & 99.7 & 98.9 \\
0.020 & 15.7 & 100 & 99.9 & 99.9 \\
0.030 & 65.8 & 100 & 100 & 100 \\
0.040 & 92.1 & 100 & 100 & 100 \\
0.050 & 98.5 & 100 & 100 & 100 \\
0.060 & 99.7 & 100 & 100 & 100 \\
\hline
\end{tabular}

Table 7 shows the loss likely to be incurred by the four cladding types at serviceability limit state (SLS) and ultimate limit state (ULS) earthquakes. Here, SLS is represented by IDR $=0.5 \%$, which is typical of yielding drift for RC frames, and the ULS is represented by IDR $=2.5 \%$ which is the maximum IDR allowed for ULS in the NZ seismic design standard [25]. As is obvious from the table, glazing and precast concrete claddings incur no loss in a SLS earthquake whereas masonry veneer and monolithic cladding incur $73 \%$ and $54 \%$ loss, respectively. In contrast, if we consider a ULS earthquake, glazing system incurs only $41 \%$ loss in comparison to $100 \%$ loss for the remaining three cladding systems. While precast panels and glazing appear to remain intact (i.e. not requiring any repair) in small-medium earthquakes, precast panels appear vulnerable to severe damage and collapse (i.e. $100 \%$ loss) during large earthquakes. In addition to losing its complete asset value, this could also potentially endanger the lives of people nearby as heavy panel blocks falling from a height can easily cause fatal injuries. Hence, the comparison between the losses for different cladding types suggests that only the glazing system appears to provide a resilient performance across different ground shaking intensities. 
Table 7: Percentage loss of the four cladding types estimated at different design limit state actions.

\begin{tabular}{ccccc} 
IDR(\%) & Glazing & Masonry & Monolithic & Precast \\
\hline 0.5 & 0 & 73 & 54 & 0 \\
2.5 & 41 & 100 & 100 & 100 \\
\hline
\end{tabular}

\section{Expected Cladding Loss (NZ\$/m2 of Floor Area)}

The expected loss in NZ dollar per square meter of floor area for different cladding systems are calculated using Equation 9. Figure 23 plots the expected loss for glazing, masonry veneer, monolithic cladding, and precast panel cladding systems at different values of interstorey drift; the loss values for different interstorey drifts are also presented in Table 8 .

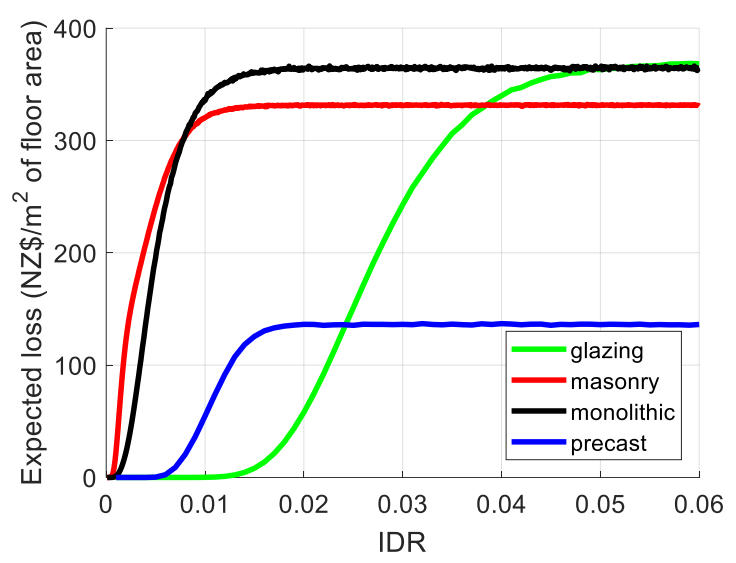

Figure 23: Comparison between expected cladding losses of the four cladding types at different IDR.

As can be inferred from Table 8, the full replacement costs of the four cladding types are 368.2, 331.9, 365, and 136.2 $\mathrm{NZ} \$ / \mathrm{m}^{2}$ of floor area, respectively. In line with what was found in the previous section, masonry veneer and monolithic cladding incur losses much earlier compared to the other two types, especially glazing. The lower loss of precast panel cladding is understandable as its cost is only about a third of the cost of glazing and masonry veneer and only $16 \%$ of monolithic cladding. Note that the maximum loss of monolithic cladding per $\mathrm{m}^{2}$ floor area is comparable to glazing and masonry veneer despite the cost of monolithic cladding being about double that of the others. This is mainly because monolithic cladding is common in industrial buildings for which the amount of cladding per unit floor area is less than half of that in commercial and residential buildings which dominate the use of glazing and masonry veneer.

The method proposed herein greatly simplifies the method of loss estimation and it is intentionally made to be simple for easy and quick application in every day design. Like the equivalent static force method, this simplified loss assessment approach is also meant to be applied in loss based design of simple regular structures, and not appropriate for very complex/unusual cases, for which a detail loss estimation procedure based on the PEER methodology needs to be followed. Nevertheless, despite the proposed method being simplified, the uncertainties in different aspects of loss estimation are accounted for without any compromise. The reliability of the final outcome (i.e. contribution functions) depends on the ability of the input data to represent the inevitable uncertainty associated with the considered variables without any bias. The concept presented in this paper has been applied previously to generate contribution functions of other structural and non-structural components, and to show how they can be used in conducting rapid loss estimation of example buildings. The contribution functions developed for all components have been applied in randomly selected case study buildings, and the actual contribution of the components was found to be well within the range of the variability of the contribution functions. In this study too, the collected density and cost data cover a reasonable range of buildings (without any conscious bias) and should apply to most cases as indicated by the case study and verification presented in the paper.

Table 8: Expected loss of the four cladding types at different IDR.

\begin{tabular}{ccccc} 
IDR & \multicolumn{4}{c}{ Expected Loss $\left(\mathbf{N Z} \mathbf{/} \mathbf{m}^{2}\right)$} \\
& Glazing & Masonry & Monolithic & Precast \\
\hline 0.002 & 0.0 & 122.4 & 22.6 & 0.0 \\
0.004 & 0.0 & 207.9 & 137.3 & 0.0 \\
0.006 & 0.0 & 268.6 & 244.2 & 2.5 \\
0.008 & 0.0 & 304.1 & 306.4 & 20.6 \\
0.010 & 0.0 & 320.4 & 336.7 & 54.3 \\
0.012 & 1.0 & 327.5 & 351.7 & 92 \\
0.014 & 4.5 & 329.3 & 358.3 & 118.7 \\
0.016 & 13.7 & 330.9 & 361.5 & 130.2 \\
0.018 & 31.4 & 331.6 & 363.6 & 134.9 \\
0.020 & 58.1 & 331.9 & 365.0 & 136.2 \\
0.030 & 243.2 & & & \\
0.040 & 339.7 & & & \\
0.050 & 363.6 & & & \\
0.060 & 368.2 & & & \\
\hline
\end{tabular}

\section{CASE STUDY}

Ideally, contribution functions for different components should be verified by comparing them against actual component damage repair cost data in earthquakes. Nevertheless, despite having access to a comprehensive repair database from EQC (Earthquake Commission) from the 2010-11 Canterbury earthquake sequence, it was not possible to extract the loss contributed by different components as the database included only the total repair cost for each house/building. Hence, an alternate approach is chosen here to verify the contribution function against the component loss calculated based on the actual quantity distribution for a case study building. This approach has an inherent limitation as the fragility and repair cost functions used in both calculations are the same; but these functions do not need further verification as the fragility functions are taken from experimental results and the repair costs are derived from data collected from builders/suppliers currently active in the industry.

To confirm the accuracy and usability of the contribution functions developed for cladding types, a case study is performed on a 10 storey RC frame building built in 1987 in Christchurch. The building was used for commercial purpose and the cladding type used was glazing. For all stories, the floor area, cladding length and inter-storey drift ratio were calculated, which are shown in Table 9. The estimated interstorey drift ratios vary between $1.62 \%$ and $0.4 \%$ [9]. Using the calculated inter-storey drift and the floor area measured from the building plans, the approximate cladding loss in a given floor can be readily determined using the loss function shown in Figure 23. Once this is repeated for all floors, the total loss from cladding for the whole building can then be obtained by adding the floor level losses. Thus the likely cladding loss at a design level (i.e. 500 year return period) seismic event as predicted using the proposed loss function comes out to be about NZ\$35,600. 
Table 9: Comparison between the predicted and the actual loss assessment for the case study.

\begin{tabular}{ccccccc} 
Floor & Area $\left(\mathbf{m}^{2}\right)$ & IDR $(\%)$ & Length $(\mathbf{m})$ & Actual $(\mathbf{N Z} \$)$ & Loss Function Prediction (NZ\$) & \% Difference \\
\hline 10 & 531 & 0.40 & 104.95 & $4.29 \mathrm{E}-06$ & $4.055 \mathrm{E}-06$ & -5.93 \\
9 & 531 & 0.67 & 104.95 & 0.326 & 0.308 & 5.94 \\
8 & 531 & 0.92 & 104.95 & 15.71 & 14.84 & 5.89 \\
7 & 531 & 1.13 & 104.95 & 206.75 & 195.23 & 5.91 \\
6 & 531 & 1.32 & 104.95 & 1256.55 & 1186.59 & 5.90 \\
5 & 531 & 1.47 & 104.95 & 4622.41 & 4365.85 & -5.88 \\
4 & 751 & 1.41 & 133.81 & 3229.23 & 3384.25 & -4.58 \\
3 & 751 & 1.52 & 133.81 & 5864.33 & 6171.53 & 4.98 \\
2 & 759 & 1.59 & 126.38 & 9316.08 & 10397.55 & -10.4 \\
1 & 719 & 1.62 & 114.80 & 8424.89 & 9848.48 & -14.5 \\
\end{tabular}

The next step to be completed is to calculate the expected loss using the actual cladding lengths. In order to do this, the actual length measured from the building plans are used along with the calculated inter-storey drifts, cladding fragility functions and the mean repair costs for different damage states. This is repeated for all floors throughout the building to obtain the total loss. The comparison between the actual calculation and the loss function estimation is shown in Table 9. As can be seen in the Table, the difference between the contribution function estimation and the detail calculation is $7.39 \%$.

Next, the actual repair cost information reported by Housing NZ [26] for some buildings after Canterbury earthquakes is used for qualitative verification of the developed contribution functions for some cladding types. Table 10 shows the cladding repair cost for different buildings damaged in Canterbury earthquakes [26]. Due to lack of complete structural details individual findings cannot be validated against the proposed contribution functions. Instead, damage states are identified based on the damage description and compared to the IDR obtained from Figure 23 using the reported values of repair cost per square meter of floor area. This comparison is shown only for the four houses with brick veneer and one with monolithic cladding, as Summerhill stone cladding and lightweight panel type cladding are not included in this study. Nevertheless, IDR values for Summerhill stone are shown in brackets using the brick veneer contribution functions to understand the error they induce when applied to other types of masonry veneers.

As can be seen from the Table, thus derived IDR values fall around or above the median drift capacities for the reported damage states (see the fragility functions in previous Sections) for the monolithic cladding and the 4 brick veneer houses (except arguably the third brick veneer house, for which the damage and repair cost were trivial and consequently the predicted IDR is at a lower end of the DS1 fragility curve). Hence, the proposed contribution functions can be argued to be readily applicable in quick estimation of cladding losses of buildings with acceptable accuracy.

Table 10: Earthquake repair cost for different cladding types damaged in Canterbury earthquakes [26].

\begin{tabular}{|c|c|c|c|c|c|}
\hline Floor Area $\left(\mathbf{m}^{2}\right)$ & Damage Description & $\begin{array}{l}\text { Repair Cost } \\
\text { (NZ\$) }\end{array}$ & $\begin{array}{l}\text { Cost per Floor } \\
\text { Area }\left(\mathrm{NZ} \$ \mathrm{~m}^{2}\right)\end{array}$ & $\begin{array}{l}\text { Damage } \\
\text { State }\end{array}$ & $\begin{array}{l}\text { IDR } \\
(\%)\end{array}$ \\
\hline \multicolumn{6}{|c|}{ Brick veneer: DS1 $\left(\mu_{I D R}=0.15 \%, \beta=0.4\right), \mathrm{DS} 2\left(\mu_{I D R}=0.35 \%, \beta=0.4\right), \mathrm{DS} 3\left(\mu_{I D R}=0.55 \%, \beta=0.4\right)$ and DS4 $\left(\mu_{I D R}=0.6 \%, \beta=0.4\right)$} \\
\hline 100 & Vertical and step cracking & 21353 & 213.5 & DS2 & 0.42 \\
\hline 98 & Minor hairline staggered cracking & 6571 & 67.1 & DS1 & 0.14 \\
\hline 110 & Minor hairline staggered cracking & 525 & 4.8 & DS1 & 0.07 \\
\hline 120 & Vertical and step cracking & 20007 & 166.7 & DS2 & 0.29 \\
\hline \multicolumn{6}{|c|}{ Stone veneer } \\
\hline 100 & Minor staggered cracking & 1488 & 14.9 & DS1 & $(0.09)$ \\
\hline 80 & Vertical and step cracking & 24675 & 308.4 & DS2 & $(0.84)$ \\
\hline 110 & Staggered crack lines & 24279 & 220.7 & DS2 & $(0.44)$ \\
\hline 92 & Major veneer and ties damage & 20698 & 225 & DS4 & $(0.45)$ \\
\hline 100 & Vertical and step cracking & 20599 & 206 & DS2 & $(0.4)$ \\
\hline 239 & Minor staggered cracking & 6550 & 27.4 & DS1 & $(0.1)$ \\
\hline \multicolumn{6}{|c|}{ Monolithic cladding: DS1 $\left(\mu_{I D R}=0.2 \%, \beta=0.4\right)$, DS2 $\left(\mu_{I D R}=0.4 \%, \beta=0.4\right)$ and DS3 $\left(\mu_{I D R}=0.7 \%, \beta=0.4\right)$} \\
\hline 90 & Minor damage & 5582 & 62 & DS1 & 0.28 \\
\hline \multicolumn{6}{|c|}{ Lightweight panels } \\
\hline 110 & Moderate damage, step cracking & 37787 & 343.5 & DS2 & - \\
\hline
\end{tabular}




\section{CONCLUSIONS}

Combining cladding distribution/density functions developed using an extensive building survey data and cladding cost functions derived using range of repair/replacement costs received from consultants, suppliers and builders together with fragility functions availed from literature, contribution functions of four main types of cladding were developed in this study. These contribution functions can be readily used in simplified building loss estimation and in loss based design methodologies like Loss Optimisation Seismic Design (LOSD).

From the field survey performed in Christchurch, common types of claddings used are identified as: masonry veneer in residential buildings, glazing and precast concrete panel in commercial buildings, and lightweight and monolithic claddings in industrial buildings. The mean cladding length to floor area ratio obtained from the survey data is found to be 0.202 (with dispersion; i.e. $\beta=0.04), 0.187(\beta=0.11$ ) and 0.083 $(\beta=0.06) \mathrm{m} / \mathrm{m} 2$ for residential, commercial and industrial buildings, respectively. The full replacement cost for glazing, masonry veneer, monolithic and precast concrete cladding systems obtained from supplier/builder survey is $565(\beta=$ 58.59), $608.3(\beta=97.66), 1250(\beta=273.4)$ and $208.3(\beta=$ $81.34) \mathrm{NZD} / \mathrm{m}^{2}$ respectively, which shows that precast concrete panel stands out as a cheap cladding option and monolithic cladding as expensive enough to potentially affect the overall construction cost of the building.

It was found that glazing, masonry veneer, monolithic and precast concrete cladding systems incur 50\% loss at inter-storey drift levels equal to $0.027,0.003,0.005$ and 0.011 , respectively. Hence it can be concluded that among the four cladding types (and the specific anchor/connection details) considered herein, masonry veneer is the most vulnerable cladding system whereas glazing is the most resilient one. Expected cladding loss for masonry veneer, monolithic and precast concrete cladding systems are maximum at $0.2 \%$ drift which are found to be 331.9 ( $\beta=90.59), 365.0(\beta=259.42)$ and 136.2 $(\beta=98.74)$ NZD per square metre of floor area, respectively. Whereas, expected glazing loss is maximum at $0.6 \%$ drift which is found to be $368.2(\beta=215.7)$ NZD per square metre of floor area. Application of the developed contribution functions to a case study scenario and some real post-earthquake damage repair cost data showed that the simplified loss estimation approach is reasonably accurate. Note that the contribution functions developed in this study is valid only for the connection details for which the fragility functions used herein were derived. Separate contribution functions may need to be developed for different cladding types or the same cladding type with different connection details.

\section{ACKNOWLEDGEMENTS}

This project was partially supported by QuakeCoRE, a New Zealand Tertiary Education Commission-funded Centre. This is QuakeCoRE publication number 0280 .

\section{REFERENCES}

1 Baird A (2014). "Seismic Performance of Precast Concrete Cladding Systems". PhD Dissertation, University of Canterbury, Christchurch, New Zealand, 544 pp

2 Knaack U, Klein T, Bilow M and Auer T (2007). "FacadesPrinciples of Construction". Berlin, Germany.

3 Dhakal RP, Pourali A, Tasligedik S, Yeow T, Baird A, MacRae G, Pampanin S and Palermo A (2016). "Seismic Performance of Non-Structural Components and Contents in Buildings: An Overview of NZ Research". Earthquake Engineering and Engineering Vibration, 15(1): 1-17.

4 Page I (2008). “Cladding Types in New Buildings". BUILD, BRANZ Ltd, Judgeford, Wellington, 55-56.
5 Deierlein GG, Krawinkler H and Cornell CA (2003). "A Framework for Performance-Based Earthquake Engineering". Proceedings of the $7^{\text {th }}$ Pacific Conference on Earthquake Engineering, Christchurch, New Zealand, 1315 February, 2003, Paper No 140.

6 Dhakal RP (2010). "First Step towards Loss Optimization Seismic Design (LOSD)". Proceedings of the $3^{\text {rd }}$ Asian Conference on Earthquake Engineering, Bangkok, Thailand, 1-3 December, 2010.

7 Dhakal RP and Saha SK (2017). "Loss Optimization Seismic Design (LOSD): Beyond Seismic Loss Assessment". Proceedings of the $16^{\text {th }}$ World Conference on Earthquake Engineering, Santiago, Chile, 9-13 January, 2017, Paper No 163.

8 Sullivan T (2016). "Use of Limit State Loss versus Intensity Models for Simplified Estimation of Expected Annual Loss". Journal of Earthquake Engineering, 20(6): 954-974.

9 Dhakal RP, Pourali A and Saha SK (2016). "Simplified Seismic Loss Functions for Suspended Ceilings and Drywall Partitions". Bulletin of the New Zealand Society for Earthquake Engineering, 49(1): 64-78.

10 Standards New Zealand (2008). "NZS 4223.1:2008 Glazing in Buildings Part 1: Glass Selection and Glazing". Standards New Zealand, Wellington, New Zealand.

11 Kaneki Y, Takeuchi T, Miyazaki K and Iwata M (2008). "Studies on Integrated Façade Engineering - Structural Performance of Integrated Facades". AIJ Journal of Technology and Design, 14(27): 137-142.

12 Thurston SJ and King AB (1992). "Two-directional Cyclic Racking of Corner Curtain Wall Glazing”. Study Report SR 44, Building Research Association of New Zealand, Judgeford, New Zealand, 78pp.

13 Pinterest (2018). https://www.pinterest.nz/pin /216032113350820280/ (Accessed 15/1/2018).

14 Truthinstone (2015). https://www.blog.stonelegends.com (Accessed 23/07/2018).

15 Pro-Stucco (2010-2013). https://www.pro-stucco.com /stucco-facts.html (Accessed 27/2/2018).

16 PCI (2007). "Architectural Precast Concrete". MNL-122, PCI Architectural Precast Concrete Manual Committee, Chicago, 609 pp.

17 Weathertight (2014). https://www.weathertight.org.nz /new-buildings/detail-solutions/wall-cladding-installation/ (Accessed 23/07/2018).

18 Eboss (2017). https://www.eboss.co.nz/, (Accessed 23/07/2018).

19 Aslani H and Miranda E (2005). "Probabilistic Earthquake Loss Estimation and Loss Disaggregation in Buildings". Blume Report 157, The John A. Blume Earthquake Engineering Center, Stanford University, Stanford, CA, USA, $383 \mathrm{pp}$.

20 Smirnov N (1948). "Table for Estimating the Goodness of Fit of Empirical Distributions". Annals of Mathematical Statistics, 19: 279-281.

21 O'Brien WC, Memari AM, Kremer PA and Behr RA (2012). "Fragility Curves for Architectural Glass in StickBuilt Glazing Systems". Earthquake Spectra, 28(2): 639665.

22 Petry S and Beyer K (2015). "Limit States of Modern Unreinforced Clay Brick Masonry Walls Subjected to InPlane Loading". Bulletin of Earthquake Engineering, 13: 1073-1095.

23 Arnold A, Uang CM and Osteraas J (2004). "Cyclic Performance and Damage Assessment of Stucco and Gypsum Sheathed Walls". Proceedings of the $13^{\text {th }}$ World 
Conference on Earthquake Engineering, Vancouver, Canada, 1-6 August, 2004, Paper No 1484.

24 Stats NZ (2017). https://www.stats.govt.nz/methods/priceindexes-for-the-construction-industry.

(Accessed 25/07/18).

25 Standards New Zealand (2004). "NZS 1170.5:2004 Structural Design Actions Part 5: Earthquake Actions New
Zealand". Standards New Zealand, Wellington, New Zealand.

26 Housing New Zealand (2014). "Technical Report on the Results of Foundation Repair Trials Conducted Following the Canterbury Earthquakes". Housing New Zealand Corporation, Christchurch, New Zealand, 203pp. 


\section{APPENDIX A. CLADDING LENGTH DISTRIBUTION}

Tables A1, A2, and A3 provide a summary of the cladding length distribution used in this study for residential, commercial and industrial buildings, respectively. For residential building's length distribution (each row in the table), building ID, number of storey, floor area, and length of monolithic, masonry and lightweight cladding in the building are presented in columns 1 to 6 , respectively. For commercial and industrial building's length distribution (each row in the table), building ID, number of storey, floor area, and the lengths of glazing, monolithic, masonry, lightweight and precast cladding in the building are presented in columns 1 to 8 , respectively. All dimensions are measured in metres.

Table A1: Cladding length distribution for residential buildings.

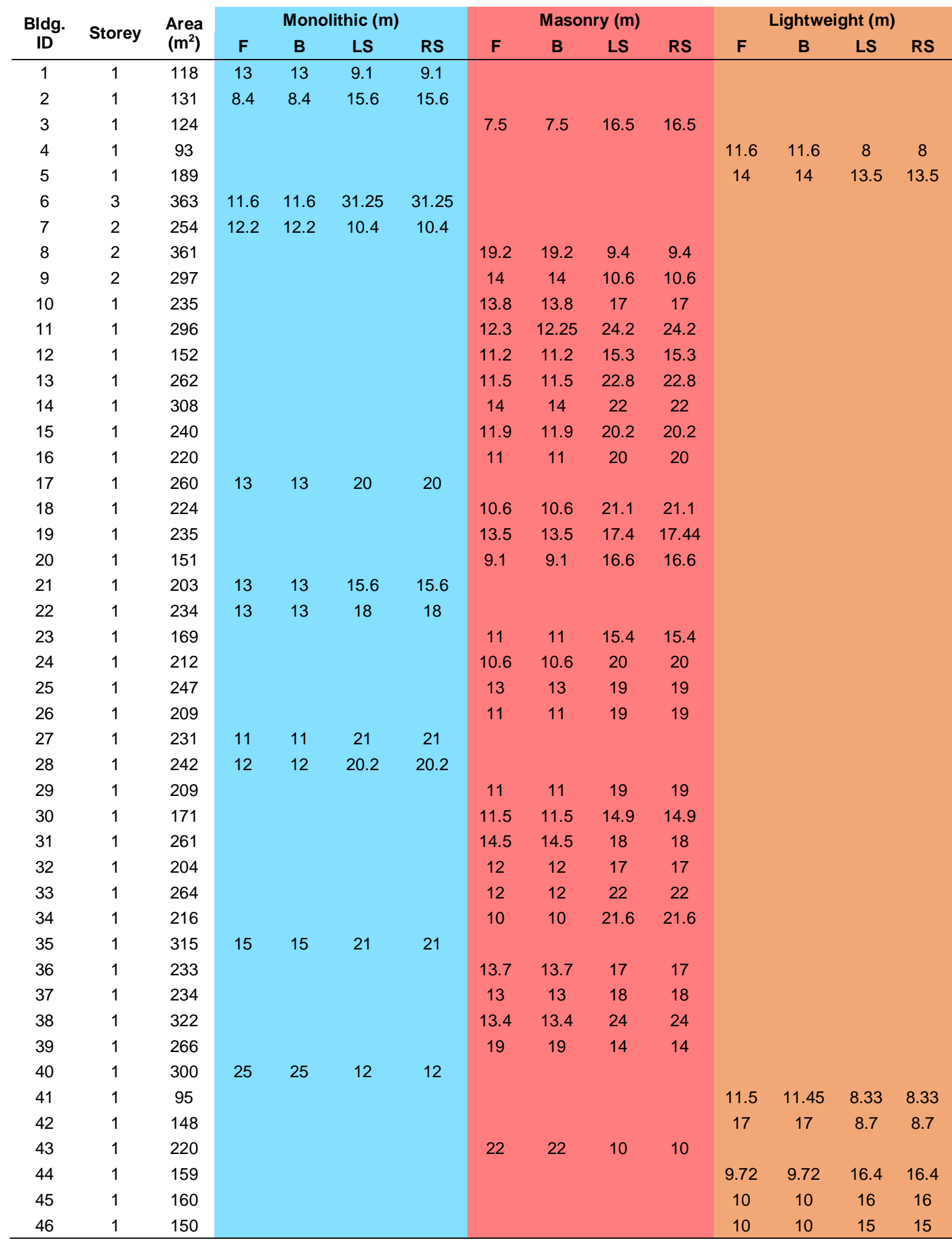

F - Front, B - Back, LS - Left Side, RS - Right Side 
Table A1: Cladding length distribution for residential buildings (Continued).

\begin{tabular}{|c|c|c|c|c|c|c|c|c|c|c|c|c|c|c|}
\hline \multirow{2}{*}{$\begin{array}{l}\text { BIdg. } \\
\text { ID }\end{array}$} & \multirow{2}{*}{ Storey } & \multirow{2}{*}{$\begin{array}{c}\text { Area } \\
\left(m^{2}\right)\end{array}$} & \multicolumn{4}{|c|}{ Monolithic (m) } & \multicolumn{4}{|c|}{ Masonry (m) } & \multicolumn{4}{|c|}{ Lightweight (m) } \\
\hline & & & $\mathbf{F}$ & B & LS & RS & $\mathbf{F}$ & B & LS & RS & $\mathbf{F}$ & B & LS & RS \\
\hline 47 & 1 & 361 & & & & & 9.5 & 9.5 & 38 & 38 & & & & \\
\hline 48 & 1 & 126 & & & & & 9 & 9 & 14 & 14 & & & & \\
\hline 49 & 1 & 145 & & & & & & & & & 10 & 10 & 14.5 & 14.5 \\
\hline 50 & 1 & 150 & 10 & 10 & 15 & 15 & & & & & & & & \\
\hline 51 & 1 & 160 & & & & & 11.2 & 11.2 & 14.3 & 14.3 & & & & \\
\hline 52 & 1 & 182 & & & & & 12.1 & 12.14 & 15 & 15 & & & & \\
\hline 53 & 1 & 186 & & & & & 11.3 & 11.3 & 16.5 & 16.5 & & & & \\
\hline 54 & 1 & 173 & 10.24 & 10.24 & 16.6 & 16.6 & & & & & & & & \\
\hline 55 & 1 & 192 & & & & & 12 & 12 & 16 & 16 & & & & \\
\hline 56 & 1 & 173 & & & & & 9.6 & 9.6 & 18 & 18 & & & & \\
\hline 57 & 1 & 169 & 11 & 11 & 15.4 & 15.4 & & & & & & & & \\
\hline 58 & 1 & 185 & & & & & 13 & 13 & 14.2 & 14.2 & & & & \\
\hline 59 & 1 & 138 & & & & & 9 & 9 & 15.3 & 15.32 & & & & \\
\hline 60 & 1 & 191 & & & & & 11.5 & 11.45 & 16.7 & 16.7 & & & & \\
\hline 61 & 1 & 140 & & & & & & & & & 14.6 & 14.6 & 9.6 & 9.6 \\
\hline 62 & 1 & 152 & & & & & 9.3 & 9.3 & 16.3 & 16.3 & & & & \\
\hline 63 & 1 & 156 & & & & & & & & & 10 & 10 & 15.6 & 15.6 \\
\hline 64 & 1 & 176 & & & & & & & & & 11 & 11 & 16 & 16 \\
\hline 65 & 1 & 168 & & & & & 10.8 & 10.8 & 15.6 & 15.6 & & & & \\
\hline 66 & 1 & 155 & & & & & 12.3 & 12.3 & 12.6 & 12.6 & & & & \\
\hline 67 & 1 & 151 & & & & & 12 & 12 & 12.6 & 12.55 & & & & \\
\hline 68 & 1 & 117 & & & & & 13 & 13 & 9 & 9 & & & & \\
\hline 69 & 1 & 138 & & & & & 8.9 & 8.9 & 15.5 & 15.5 & & & & \\
\hline 70 & 1 & 129 & & & & & & & & & 13.6 & 13.6 & 9.5 & 9.5 \\
\hline 71 & 1 & 294 & & & & & 18 & 18 & 24 & 24 & & & & \\
\hline 72 & 1 & 432 & & & & & 18 & 18 & 24 & 24 & & & & \\
\hline 73 & 1 & 270 & & & & & 18 & 18 & 22 & 22 & & & & \\
\hline 74 & 1 & 356 & & & & & 16.3 & 16.3 & 26 & 26 & & & & \\
\hline 75 & 1 & 424 & & & & & 16.6 & 16.62 & 25.5 & 25.5 & & & & \\
\hline 76 & 1 & 338 & 15.5 & 15.5 & 21.8 & 21.8 & & & & & & & & \\
\hline 77 & 1 & 234 & & & & & 11.8 & 11.8 & 19.8 & 19.8 & & & & \\
\hline 78 & 1 & 320 & & & & & 16 & 16 & 20 & 20 & & & & \\
\hline 79 & 1 & 344 & & & & & 16.3 & 16.3 & 25 & 25 & & & & \\
\hline 80 & 1 & 306 & & & & & 16.9 & 16.9 & 21.4 & 21.4 & & & & \\
\hline 81 & 1 & 230 & & & & & 14.4 & 14.4 & 16 & 16 & & & & \\
\hline 82 & 1 & 406 & & & & & 16.9 & 16.9 & 24 & 24 & & & & \\
\hline 83 & 1 & 295 & & & & & 15.2 & 15.23 & 19.4 & 19.36 & & & & \\
\hline 84 & 1 & 359 & & & & & 16.7 & 16.7 & 21.5 & 21.5 & & & & \\
\hline 85 & 1 & 345 & & & & & 15 & 15 & 23 & 23 & & & & \\
\hline 86 & 1 & 360 & & & & & 12 & 12 & 30 & 30 & & & & \\
\hline 87 & 1 & 279 & & & & & 13.2 & 13.2 & 24 & 24 & & & & \\
\hline 88 & 1 & 384 & & & & & 16.5 & 16.5 & 23.3 & 23.3 & & & & \\
\hline 89 & 1 & 324 & & & & & 17.7 & 17.7 & 26 & 26 & & & & \\
\hline 90 & 1 & 362 & & & & & 13.4 & 13.4 & 27 & 27 & & & & \\
\hline 91 & 1 & 165 & & & & & 11 & 11 & 15 & 15 & & & & \\
\hline 92 & 1 & 170 & & & & & 10 & 10 & 17 & 17 & & & & \\
\hline 93 & 1 & 160 & & & & & 10 & 10 & 16 & 16 & & & & \\
\hline 94 & 1 & 160 & & & & & 12 & 12 & 16 & 16 & & & & \\
\hline 95 & 1 & 162 & & & & & 11.5 & 11.5 & 14 & 14 & & & & \\
\hline 96 & 1 & 149 & & & & & 9.4 & 9.4 & 15.8 & 15.8 & & & & \\
\hline 97 & 1 & 155 & & & & & 9.6 & 9.6 & 16.1 & 16.11 & & & & \\
\hline 98 & 1 & 178 & & & & & 12 & 12 & 14.8 & 14.8 & & & & \\
\hline 99 & 1 & 123 & & & & & 8.33 & 8.33 & 14.8 & 14.8 & & & & \\
\hline 100 & 1 & 147 & & & & & 9.8 & 9.8 & 15 & 15 & & & & \\
\hline
\end{tabular}

F - Front, B - Back, LS - Left Side, RS - Right Side 
Table A2: Cladding length distribution for commercial buildings.

\begin{tabular}{|c|c|c|c|c|c|c|c|c|c|c|c|c|c|c|c|c|c|}
\hline \multirow{2}{*}{$\begin{array}{l}\text { Bldg. } \\
\text { ID }\end{array}$} & \multirow{2}{*}{ Storey } & \multirow{2}{*}{$\begin{array}{l}\text { Area } \\
\left(m^{2}\right)\end{array}$} & \multicolumn{3}{|c|}{ Glazing $(m)$} & \multicolumn{3}{|c|}{ Monolithic (m) } & \multicolumn{3}{|c|}{ Masonry (m) } & \multicolumn{3}{|c|}{$\begin{array}{l}\text { Lightweight } \\
(\mathrm{m})\end{array}$} & \multicolumn{3}{|c|}{ Precast (m) } \\
\hline & & & $\mathbf{F}$ & B & $\mathbf{S}$ & $\mathbf{F}$ & B & s & $\mathbf{F}$ & B & $\mathbf{s}$ & $\mathbf{F}$ & B & $s$ & $\mathbf{F}$ & B & s \\
\hline 1 & 2 & 800 & 20 & 20 & 40 & & & & & & & & & & & & \\
\hline 2 & 4 & 2275 & & & 32 & & & & & & & & & & 50 & 50 & 35 \\
\hline 3 & 3 & 6000 & 27 & & & & & & & & & 33 & 60 & 72 & 100 & 100 & 60 \\
\hline 4 & 3 & 2000 & 60 & 30 & & 90 & 150 & 150 & & & & & & & & & \\
\hline 5 & 5 & 1650 & 40 & 40 & 25 & & & & & & & & & & & & \\
\hline 6 & 1 & 600 & 10 & & 20 & 10 & & 10 & & & & & & & & & \\
\hline 7 & 2 & 900 & & 14 & & & & & & & & & & & 30 & 12 & 30 \\
\hline 8 & 1 & 750 & 8 & 8 & 7 & 12 & 12 & 18 & & & & & & & & & \\
\hline 9 & 1 & 1250 & 50 & 50 & 28 & & & & & & & & & & & & \\
\hline 10 & 2 & 1250 & 20 & 20 & 16 & & & & & & & 80 & 80 & 40 & & & \\
\hline 11 & 2 & 400 & & & & & & & & 10 & 10 & & & & & & \\
\hline 12 & 1 & 500 & 2 & & & & & & & & & 5 & 10 & 20 & 25 & 25 & 25 \\
\hline 13 & 1 & 1080 & 33 & & 20 & & & & & 36 & 13 & 5 & 0 & 0 & 0 & 0 & 0 \\
\hline 14 & 1 & 400 & 2 & 22 & 24 & & & & & & & 20 & 20 & 30 & & & \\
\hline 15 & 1 & 400 & 5 & 22 & 24 & & & & & & & 12 & & & & & \\
\hline 16 & 1 & 800 & 28 & 0 & 35 & & & & & 24 & 5 & & & & & & \\
\hline 17 & 1 & 800 & 24 & 0 & 0 & & & & & & 40 & & & & & & \\
\hline 18 & 1 & 150 & 8 & & & 0 & 10 & 14 & & & & & & & & & \\
\hline 19 & 1 & 400 & 20 & & & & & & & & & & 20 & 20 & & & \\
\hline 20 & 1 & 400 & 20 & & 20 & 3 & 22 & 1 & & & & & 20 & 20 & & 20 & 10 \\
\hline 21 & 1 & 484 & 20 & & & 3 & & 1 & & & & & & & & 20 & 10 \\
\hline 22 & 1 & 300 & 10 & 10 & 15 & & & & & & & & & & & & \\
\hline 23 & 1 & 300 & 10 & 10 & 15 & & & & & & & & & & & & \\
\hline 24 & 1 & 240 & 16 & 2 & & & 16 & 30 & & & & & & & & & \\
\hline 25 & 1 & 240 & 16 & 2 & & & 16 & 30 & & & & 10 & 10 & & & & \\
\hline 26 & 1 & 900 & 15 & & & & & & & & & 15 & 15 & 40 & & 15 & 60 \\
\hline 27 & 1 & 600 & & & & & & & & & & 15 & & 20 & & 15 & 40 \\
\hline 28 & 1 & 900 & 20 & 20 & & & & & & & & 10 & 10 & 30 & & & \\
\hline 29 & 1 & 300 & & & & & & & & & & & & & & & \\
\hline 30 & 1 & 100 & & & & & & & & & & & & & 10 & 10 & 10 \\
\hline 31 & 1 & 675 & & & & & & & & & & 15 & 15 & 45 & & & 10 \\
\hline 32 & 1 & 675 & 12 & 12 & 40 & & & & & & & 15 & 15 & 30 & & & \\
\hline 33 & 1 & 450 & & & & & & & & & & & & & 15 & 15 & 30 \\
\hline 34 & 1 & 6000 & & & & & & & & & & 20 & 20 & & & & \\
\hline 35 & 1 & 700 & 20 & 20 & 35 & & & & & & & & & & & & \\
\hline 36 & 1 & 736 & 15 & 15 & 30 & & & & 5 & 5 & 5 & & & & 10 & 10 & 8 \\
\hline 37 & 1 & 184 & 8 & 8 & & & & & & & 25 & & & & & & \\
\hline 38 & 6 & 2340 & 270 & 270 & 330 & & & & & & & & & & & & \\
\hline 39 & 1 & 360 & 18 & & & & & & & 18 & 20 & & & & & & \\
\hline 40 & 1 & 360 & & & & & & & & & & & & & 7 & 18 & 20 \\
\hline 41 & 1 & 450 & & & & & & & 15 & 15 & 32 & & & & & & \\
\hline 42 & 1 & 360 & 8 & & & & & & 2 & 18 & & & & & & 8 & 10 \\
\hline 43 & 1 & 690 & & & & & & & & & & 25 & 25 & 30 & & & \\
\hline 44 & 1 & 400 & 10 & & & & & & & & & & & & & 10 & 40 \\
\hline 45 & 1 & 400 & & & & & & & & & & 10 & 10 & 40 & & & \\
\hline 46 & 1 & 600 & & & & & & & 18 & 18 & 40 & & & & & & \\
\hline 47 & 1 & 510 & 10 & & & & & & & & & & & 28 & 3 & 8 & 0 \\
\hline 48 & 1 & 600 & 30 & 0 & 20 & & 30 & & & & & & & & & & \\
\hline 49 & 1 & 600 & 30 & & 20 & & 30 & & & & & & & & & & \\
\hline 50 & 1 & 300 & 20 & 0 & 5 & & & & 10 & 5 & & & & & & & \\
\hline 51 & 1 & 300 & 20 & & 5 & & & & 10 & 5 & & & & & & & \\
\hline 52 & 20 & 600 & & & & & & & & & & & & & & & 20 \\
\hline 53 & 7 & 2888 & & 76 & & 33 & & 30 & & & & & & & & & \\
\hline
\end{tabular}

F - Front, B - Back, S - Side 
Table A2: Cladding length distribution for commercial buildings (Continued).

\begin{tabular}{|c|c|c|c|c|c|c|c|c|c|c|c|c|c|c|c|c|c|}
\hline \multirow{2}{*}{$\begin{array}{l}\text { Bldg. } \\
\text { ID }\end{array}$} & \multirow{2}{*}{ Storey } & \multirow{2}{*}{$\begin{array}{l}\text { Area } \\
\left(m^{2}\right)\end{array}$} & \multicolumn{3}{|c|}{ Glazing (m) } & \multicolumn{3}{|c|}{$\begin{array}{l}\text { Monolithic } \\
\text { (m) }\end{array}$} & \multicolumn{3}{|c|}{ Masonry (m) } & \multicolumn{3}{|c|}{$\begin{array}{l}\text { Lightweight } \\
(\mathrm{m})\end{array}$} & \multicolumn{3}{|c|}{ Precast (m) } \\
\hline & & & $\mathbf{F}$ & B & $\mathbf{S}$ & $\mathbf{F}$ & B & $\mathrm{s}$ & $\mathbf{F}$ & B & $s$ & $\mathbf{F}$ & B & s & $F$ & B & $S$ \\
\hline 54 & 1 & 400 & 15 & 15 & & & & & 20 & 20 & 20 & & & & & & \\
\hline 55 & 3 & 3600 & 90 & 90 & 20 & & & & 30 & 30 & 10 & & & & & & \\
\hline 56 & 2 & 2400 & & & & & & & & & & 120 & 120 & 80 & & & \\
\hline 57 & 2 & 175 & & & & & & & & & & 35 & 5 & & & & \\
\hline 58 & 11 & 525 & 18 & 18 & 7 & & & & & & & & & & 18 & 18 & 7 \\
\hline 59 & 11 & 589 & 15 & 15 & 8 & & & & & & & & & & 15 & 15 & 8 \\
\hline 60 & 15 & 600 & 200 & 200 & 100 & & & & & & & 100 & 100 & 50 & 200 & 200 & 10 \\
\hline 61 & 4 & 1600 & 40 & 40 & 10 & & & & 40 & 40 & 80 & & & & & & \\
\hline 62 & 1 & 625 & 5 & 5 & 3 & 20 & 20 & 15 & & & & & & & & & \\
\hline 63 & 1 & 600 & 10 & 10 & 20 & 30 & 30 & 15 & & & & & & & & & \\
\hline
\end{tabular}

F - Front, B - Back, S - Side

Table A3: Cladding length distribution for industrial buildings.

\begin{tabular}{|c|c|c|c|c|c|c|c|c|c|c|c|c|c|c|c|c|c|}
\hline \multirow{2}{*}{$\begin{array}{l}\text { BIdg. } \\
\text { ID }\end{array}$} & \multirow[t]{2}{*}{ Storey } & \multirow{2}{*}{$\begin{array}{c}\text { Area } \\
\left(m^{2}\right)\end{array}$} & \multicolumn{3}{|c|}{ Glazing (m) } & \multicolumn{3}{|c|}{ Monolithic (m) } & \multicolumn{3}{|c|}{ Masonry (m) } & \multicolumn{3}{|c|}{$\begin{array}{l}\text { Lightweight } \\
\text { (m) }\end{array}$} & \multicolumn{3}{|c|}{ Precast $(m)$} \\
\hline & & & $\mathbf{F}$ & B & S & $\mathbf{F}$ & B & $\mathbf{s}$ & $\mathbf{F}$ & B & $\mathbf{s}$ & $\mathbf{F}$ & B & $\mathrm{s}$ & $\mathbf{F}$ & B & $\mathbf{S}$ \\
\hline 1 & 1 & 8100 & & & & 90 & 90 & 90 & & & & & & & & & \\
\hline 2 & 1 & 3750 & 20 & & & 50 & 50 & & & & & & & 75 & 40 & 40 & \\
\hline 3 & 1 & 1500 & & & 3 & 20 & 20 & 10 & & & & & & & & & \\
\hline 4 & 1 & 2250 & & & & & & & & & & 50 & 60 & 32 & & & \\
\hline 5 & 1 & 19500 & & & 3 & & 5 & & & & & & & & 150 & 150 & 130 \\
\hline 6 & 1 & 4590 & & & & & & & & & & 54 & 54 & 85 & & & \\
\hline 7 & 1 & 1125 & & & 5 & & & & & & & 54 & 54 & 80 & & & \\
\hline 8 & 1 & 28000 & & & & 56 & 200 & & 75 & & & & & & & & \\
\hline 9 & 1 & 48000 & & & & 250 & 250 & 120 & & & & & & & & & \\
\hline 10 & 1 & 600 & & & & & & & & & & & & & 10 & 10 & 40 \\
\hline 11 & 1 & 1350 & & & & 50 & 20 & 20 & & & & & & & & & 100 \\
\hline 12 & 1 & 4000 & & & & 100 & 100 & 40 & & & & & & & & & \\
\hline 13 & 1 & 4800 & & & & & & & 80 & & 60 & & 80 & & & & \\
\hline 14 & 1 & 2250 & & & & 25 & 25 & 30 & & & & & & & 40 & 40 & 0 \\
\hline 15 & 1 & 2400 & & & & & & & & & & 60 & 60 & 40 & & & \\
\hline 16 & 1 & 2400 & & & & & & & & & & 60 & 60 & 40 & & & \\
\hline 17 & 1 & 1125 & & & & & & & & & & 45 & 45 & 25 & & & \\
\hline 18 & 1 & 10800 & & & & & & 25 & & & & 180 & 180 & 60 & & & \\
\hline 19 & 1 & 784 & 20 & & & & & & 3 & 28 & 28 & & & & & & \\
\hline 20 & 1 & 2250 & & & & & & & & & & 5 & & & & 45 & 50 \\
\hline 21 & 1 & 2250 & 25 & & & & & & & & & & & & & 50 & 45 \\
\hline 22 & 1 & 1200 & & & & 50 & 50 & 10 & & & & & & & & & \\
\hline 23 & 1 & 2100 & & & & 70 & 70 & 30 & & & & & & & & & \\
\hline 24 & 1 & 900 & 20 & & & 10 & 30 & 30 & & & & & & & & & \\
\hline 25 & 1 & 800 & 10 & & & 10 & 20 & 40 & & & & & & & & & \\
\hline 26 & 1 & 600 & & & & & & & & & & & & & 30 & 30 & 5 \\
\hline 27 & 1 & 300 & & & & & & & & & & & & & & & \\
\hline 28 & 1 & 600 & & & & 15 & 15 & 30 & & & & & & & & & \\
\hline 29 & 1 & 750 & & & & 50 & 50 & 15 & & & & & & & & & \\
\hline 30 & 1 & 1200 & & & & 20 & 20 & 60 & & & & & & & & & \\
\hline 31 & 1 & 2000 & 5 & & & 10 & & & 30 & & & 20 & & & & & \\
\hline 32 & 1 & 4740 & & & & & & & & & & & & & 78 & 78 & 60 \\
\hline 33 & 1 & 1500 & 10 & 10 & 10 & & & & & & & 20 & 20 & 10 & & & \\
\hline 34 & 1 & 1400 & & & & 10 & 70 & 20 & & & & & & & & & \\
\hline 35 & 1 & 1600 & 10 & 20 & & 10 & 10 & 30 & & & & & & & & & \\
\hline
\end{tabular}

F - Front, B - Back, S - Side 


\section{APPENDIX B. CLADDING SYSTEM REPAIR COST}

Repair cost data obtained from the supplier and builder survey for glazing, masonry, monolithic and precast cladding systems are shown in Table B1. Cladding types, damage state, type of damage, repair work required, number of responses, lower and upper bounds of the repair cost are presented in columns 1 to 7 , respectively.

Table B1: Repair cost for cladding systems.

\begin{tabular}{|c|c|c|c|c|c|c|}
\hline $\begin{array}{l}\text { Cladding } \\
\text { Types }\end{array}$ & $\begin{array}{l}\text { Damage } \\
\text { State }\end{array}$ & Damage Types & Repair Work Required & Response & $\begin{array}{l}\text { Lower Bound } \\
\text { of Repair } \\
\text { Cost }\left(\$ / \mathrm{m}^{2} \text { of }\right. \\
\text { Surface Area) }\end{array}$ & $\begin{array}{l}\text { Upper Bound } \\
\text { of Repair } \\
\text { Cost }\left(\$ / \mathrm{m}^{2} \text { of }\right. \\
\text { Surface Area) }\end{array}$ \\
\hline \multirow{3}{*}{ Glazing } & DS1 & Gasket failure & Rubber in new gasket & 1 & 66 & 80 \\
\hline & DS2 & Glass cracking & $\begin{array}{c}\text { Glaze new glass with } \\
\text { new gasket }\end{array}$ & 1 & 490 & 640 \\
\hline & DS3 & Glass fallout & $\begin{array}{c}\text { Glaze new glass with } \\
\text { new gasket }\end{array}$ & 1 & 490 & 640 \\
\hline \multirow{12}{*}{ Masonry } & \multirow{3}{*}{ DS1 } & \multirow{3}{*}{ Stair step crack visible } & \multirow{3}{*}{$\begin{array}{l}\text { Repair damage mortar } \\
\text { and repoint }\end{array}$} & 1 & 250 & 400 \\
\hline & & & & 2 & 250 & 300 \\
\hline & & & & 3 & 200 & 300 \\
\hline & \multirow{4}{*}{ DS2 } & \multirow{3}{*}{$\begin{array}{l}\text { Crack propagate through } \\
\text { brick }\end{array}$} & \multirow{3}{*}{ Replace new bricks } & 1 & 300 & 400 \\
\hline & & & & 2 & 350 & 400 \\
\hline & & & & 3 & 350 & 450 \\
\hline & & \multirow{3}{*}{$\begin{array}{l}\text { Concentration in } \\
\text { diagonal crack }\end{array}$} & \multirow{3}{*}{ Replace new panel } & 1 & 450 & 550 \\
\hline & \multirow[t]{3}{*}{ DS3 } & & & 2 & 400 & 600 \\
\hline & & & & 3 & 400 & 500 \\
\hline & & \multirow{3}{*}{ Shearing-off of corners } & \multirow{3}{*}{ Recladding } & 1 & 550 & 750 \\
\hline & \multirow[t]{2}{*}{ DS4 } & & & 2 & 500 & 700 \\
\hline & & & & 3 & 400 & 750 \\
\hline \multirow{12}{*}{ Monolithic } & \multirow{4}{*}{ DS1 } & \multirow{4}{*}{ Hairline cracks } & \multirow{4}{*}{$\begin{array}{l}\text { Stucco crack routing } \\
\text { and filling }\end{array}$} & 1 & 60 & 110 \\
\hline & & & & 2 & 90 & 110 \\
\hline & & & & 3 & 50 & 90 \\
\hline & & & & 4 & 130 & 130 \\
\hline & \multirow{4}{*}{ DS2 } & \multirow{4}{*}{ Extension of cracks } & \multirow{4}{*}{ Cover wallboard cracks } & 1 & 500 & 700 \\
\hline & & & & 2 & 600 & 1100 \\
\hline & & & & 3 & 800 & 1300 \\
\hline & & & & 4 & 600 & 800 \\
\hline & \multirow{4}{*}{ DS3 } & \multirow{4}{*}{ Branching of cracks } & \multirow{4}{*}{ Replace new cladding } & 1 & 900 & 2000 \\
\hline & & & & 2 & 600 & 1800 \\
\hline & & & & 3 & 200 & 1000 \\
\hline & & & & 4 & 200 & 1200 \\
\hline \multirow{3}{*}{ Precast } & DS1 & Galling of washer & Inspect connections & 1 & 22.5 & 84.2 \\
\hline & DS2 & $\begin{array}{c}\text { Bending of washer and } \\
\text { bolt }\end{array}$ & $\begin{array}{l}\text { Repair/replace } \\
\text { connections }\end{array}$ & 1 & 31.9 & 127.6 \\
\hline & DS3 & $\begin{array}{l}\text { Crack in the cladding } \\
\text { panel }\end{array}$ & Install new cladding & 1 & 104.2 & 416.7 \\
\hline
\end{tabular}

